\title{
The Association of Social Anxiety and Parenting Factors with Adolescent Use of Facebook
}

Brian Creasy

West Virginia University

Follow this and additional works at: https://researchrepository.wvu.edu/etd

\section{Recommended Citation}

Creasy, Brian, "The Association of Social Anxiety and Parenting Factors with Adolescent Use of Facebook" (2012). Graduate Theses, Dissertations, and Problem Reports. 246.

https://researchrepository.wvu.edu/etd/246

This Dissertation is protected by copyright and/or related rights. It has been brought to you by the The Research Repository @ WVU with permission from the rights-holder(s). You are free to use this Dissertation in any way that is permitted by the copyright and related rights legislation that applies to your use. For other uses you must obtain permission from the rights-holder(s) directly, unless additional rights are indicated by a Creative Commons license in the record and/ or on the work itself. This Dissertation has been accepted for inclusion in WVU Graduate Theses, Dissertations, and Problem Reports collection by an authorized administrator of The Research Repository @ WVU.

For more information, please contact researchrepository@mail.wvu.edu. 
The Association of Social Anxiety and Parenting Factors with Adolescent Use of Facebook

Brian Creasy, M.A.

\author{
Dissertation submitted to the \\ Eberly College of Arts and Sciences \\ at West Virginia University \\ in partial fulfillment of the requirements \\ for the degree of
}
Doctor of Philosophy
in
Psychology
Tracy L. Morris, Ph.D., Chair
Karen Anderson, Ph.D.
Elisa Krackow, Ph.D.
Cheryl McNeil, Ph.D.
David Westerman, Ph.D.

Department of Psychology

Morgantown, West Virginia

2012

Keywords: social anxiety, social networking, Facebook, parenting, adolescent 


\begin{abstract}
The Association of Social Anxiety and Parenting Factors with Adolescent Use of Facebook Brian August Creasy
\end{abstract}

Computers and the Internet play a substantial role in how adolescents communicate with one another. Social networking websites, in particular, are a popular medium used by adolescents in which users can develop and maintain a large number of relationships from a single profile page. Facebook represents one of the most widely used social networking websites; however, little is known about the types of factors that are associated with the way in which adolescents use it. The present study examined the association of social anxiety and parenting with adolescent Facebook use. One hundred and sixty-two adolescents between the ages of 16 and 18 completed online questionnaires that measured social anxiety, Facebook use, and parenting factors (control, monitoring, and limit setting). In addition, 192 parents completed questionnaires concerning knowledge of their child's Facebook use as well as their own monitoring and limit setting behaviors regarding Facebook. Contrary to what was hypothesized, results indicated that adolescents with moderate to high social anxiety were just as likely as those with little to no social anxiety to have an active Facebook account. In addition, both groups used Facebook to maintain existing relationships (as opposed to developing new ones) and they used it equally as much. A higher proportion of less socially anxious adolescents had more friends on their Facebook profile page, and this lends partial support for the "rich get richer" hypothesis in which more socially outgoing individuals are using Facebook to expand their existing large offline social network. With respect to parenting, fathers were significantly more controlling of their daughter's behavior compared to their sons. In addition, mothers engaged in significantly more monitoring and limit setting of their child's Facebook use compared to fathers. These results 
suggest that mothers may be taking a more active role in monitoring and regulating the online behavior of their children. 


\section{Table of Contents}

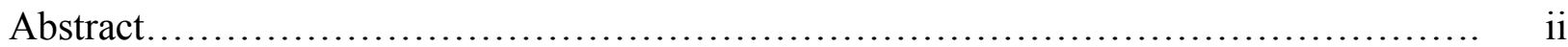

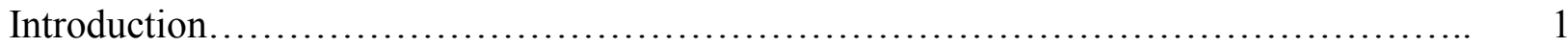

Social Networking Websites...................................................... 1

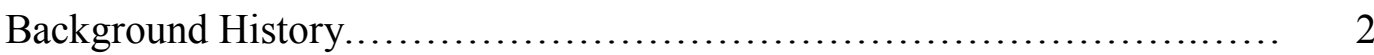

Facebook.............................................................. 2

Social Anxiety..................................................... 5

Association with online communication............................. 8

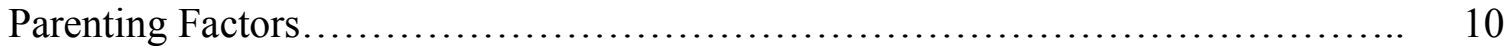

Parenting Styles.................................................... 11

Parenting and Social Networking Websites............................. 13

Statement of the Problem........................................................ 14

Research Questions and Hypotheses...................................... 15

Method............................................................................ 16

Participants......................................................... 16

Parent Report Measures................................................... 17

Adolescent Report Measures............................................... 18

Procedure................................................................... 21

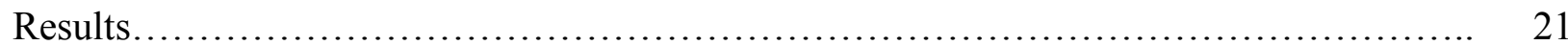

Preliminary Analyses................................................. 21

Tests of Hypotheses.................................................. 24

Exploratory Analyses................................................... 28

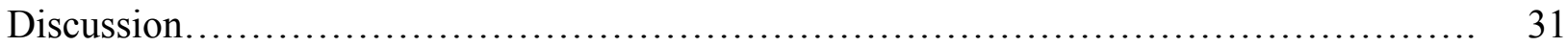

Social Anxiety and Facebook Use...................................... 32

Social Anxiety and Parental Control.......................................... 33 
Parenting Factors......................................................... 33

Risky Online Behavior............................................................................. 34

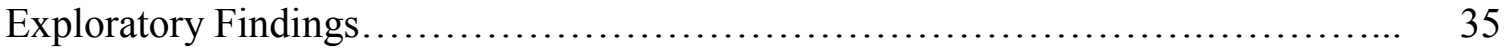

Limitations.................................................................. 38

Future Directions............................................................ 39

Conclusion...................................................................... 41

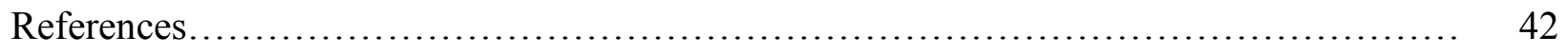

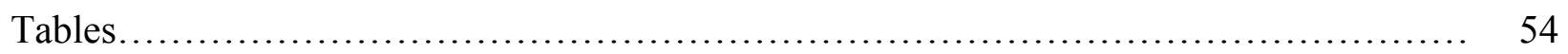

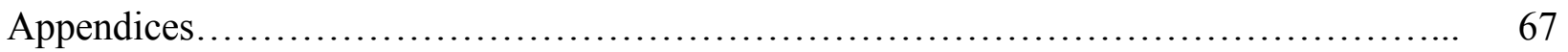


The Association of Social Anxiety and Parenting Factors with Adolescent Use of Facebook Computers and the Internet play a substantial role in how adolescents socialize with one another (Hinduja \& Patchin, 2008). It has been estimated that $93 \%$ of youth in the U.S., between the ages of 12 and 17, use the Internet regularly and these numbers will continue to grow as online resources become more widely available (Lenhart \& Madden, 2007). Moreover, for adolescent populations, the Internet provides a relatively unrestricted environment to experiment with their identity formation (Williams \& Merten, 2008). Social networking websites, in particular, provide a unique forum for developing and sustaining friendships. Lenhart and Madden (2007) found that at least 55\% of teenage youth in the U.S. have created an online personal profile page on a social networking website. These websites represent a substantial portion of adolescent Internet use; however, there is currently very little research that examines the types of factors that are associated with adolescent use of social networking websites. Furthermore, it is unclear what parenting factors may be associated with an adolescent's online behavior. Specifically, parents may not be aware of the type of information that their teenager may be disclosing and accessing when logged on to a social networking website. Moreover, parenting style may be related to adolescent online behavior as well as the parents' knowledge of these behaviors.

\section{Social Networking websites}

Boyd and Ellison (2008) defined social networking websites as "web-based services that allow individuals to construct a public or semi-public profile within a bounded system, articulate a list of other users with whom they share a connection, and view and traverse their list of connections and those made by others within the system" (p. 211). The three main types of websites are dating, common interest, and friendship networking and each of these website 
categories offer specific features based on the type of relationship that the user is interested in pursuing (Valkenburg, Peter, \& Schouten, 2006).

The history of online social networks dates back to 1978 when Murray Turoff and S. Roxanne Hiltz established the Electronic Information Exchange System for the U.S. Office of Civilian Defense. This allowed users to e-mail other people and gave them access to a list server. Nearly 20 years later, Sixdegrees.com was introduced, and this gave the average consumer the ability to network online through a specified website. Other major social networking sites would soon follow such as Ryze.com (2001), Friendster.com (2003), MySpace.com (2004) and finally, Facebook.com (2006). Some of the more popular social networking websites like MySpace and Facebook are growing at such an alarming rate that many companies are restricting access to these websites due to a perceived loss in workplace productivity (Boyd \& Ellison, 2008). At present, no reliable statistics exist with respect to the actual number of people who use social networking websites consistently; however, due to the overwhelming growth of social networking websites over the past decade, it is rare to find an adolescent or young adult who does not have a profile page on either Facebook or MySpace (Boyd \& Ellison, 2008; Lenhart \& Madden, 2007).

MySpace, a popular social networking site among adolescents and young adults, attracts over 50 million unique visitors every month (Acar, 2008). It was created in 2004 and began to attract three distinct types of users. These included musicians, adolescent/college students, and the post-college urban social crowd (Boyd \& Ellison, 2008). To date, a lot of the research on adolescent use of social networking websites has been conducted on MySpace users; however, many of the existing studies have been conducted using a random selection of profiles in which the investigator was unable to verify that the information being collected was not fictitious. 
One of the most popular social networking websites, Facebook, has received less research attention with adolescent populations. Recent figures indicate that Facebook is the most visited social networking website, with over 800 million active users worldwide (Kazeniac, 2009; Zuckerberg et al., 2011). In addition, Facebook represents one of the fastest growing social networking websites in terms of new users and is the most visited website for college populations (Fogel \& Negmad, 2008). Previous studies on Facebook use in undergraduate populations have shown that over $90 \%$ of college students have created a Facebook profile page (Stutzman, 2006).

According to Boyd and Ellison (2008), Facebook was created in 2004 by a college undergraduate student, Mark Zuckerberg, as a means of social networking exclusively among students at Harvard University. It soon became accessible to over 2000 other colleges and universities throughout the United States. In order to expand its user base, the site was made available to high school populations in 2005 . The following year, access was granted to anyone with a valid e-mail account and this included companies and commercial organizations.

The role of Facebook continues to expand and adapt as the political climate has shifted throughout many regions worldwide. In addition to serving as a means for individuals to connect and share information with one another, it has served as a crucial means of communication for major protest movements worldwide, and this has led to strict censorship by authoritarian governments. Domestically, it is now common for politicians to have a profile page in order to connect to their constituents. For instance, Powell (2011) found that people who accessed social networking sites of a particular candidate in the 2008 presidential election felt a greater amount of homophily, or an affinity for being around similar people, than those not engaged in social networking. Social networking is an appealing option for political candidates as it represents a 
cheap and efficient means to post messages and communicate with constituents during their campaign and throughout their political tenure. Also, many successful U.S. businesses have established a presence on Facebook for customers to be able to contact them, access information about the company, and purchase commercial products.

In order to be able to access Facebook, a potential user must first create an individual profile. Facebook users must include a name for the account and are encouraged to post background information such as education, employment, romantic status, political affiliation, and special interests. Potential users also may post additional contact information on their page; however, this is highly discouraged by many users because of safety concerns.

Facebook provides a forum in which a user can post messages about themselves on their profile page, send public messages to other users, post pictures on their page that are viewable on other users' accounts, and add links to songs, games, or video clips that other users can play. Research suggests that most people use social networking sites to maintain existing relationships and to search for people whom they have previously met offline as opposed to attempting to meet new people online (Kay, 2007; Ellison, Steinfield, \& Lampe, 2007; Sheldon, 2008; Pempek, Yermolayeva, \& Calvert, 2009; Kujath, 2011). For example, Subrahmanyam, Reich, Waiechterb, and Guadalupe (2008) interviewed 110 college students about their social networking site use and most users reported that they would only add friends to their network whom they met offline. In their sample, only a small number of students reported that they created a social networking profile to meet new people and make new friends. Kujath (2011) also found that while college students are highly unlikely to use Facebook to start new friendships, they do use it as a means to investigate people that they have met offline. In this instance, 
Facebook serves as a screener of sorts where people can gain more information about an individual before pursuing a friendship or romantic relationship offline.

While the literature on Facebook use with respect to young adults demonstrates that they are using Facebook to maintain existing friendships, research with adolescents is less clear and focuses mostly on Internet communication in general. Subrahmanyam and Greenfield (2008) found that adolescents use Internet communication tools primarily to reinforce existing relationships. However, they also suggest that one benefit for adolescents who interact with strangers online may be to relieve social anxiety. Peter, Valkenburg, and Schouten (2006) also found that younger adolescents were more likely to communicate with strangers via the Internet and this may be due to having less independence compared to their older peers. Another study on adolescent Internet use showed that online interactions with unknown peers helped adolescents cope with social rejection (Gross, Juvonen, \& Gable, 2002).

\section{Social Anxiety}

Social anxiety has been characterized as an exaggerated sensitivity and concern about negative evaluation by others and social failure (McTeague et al, 2009). In addition, Greco and Morris (2005) describe it as the trademark characteristic of social phobia, a condition in which the Diagnostic and Statistical Manual of Mental Disorders (DSM-IV) defines as "marked and persistent fear of one or more social or performance situations in which the person is exposed to unfamiliar people or to possible scrutiny by others" (American Psychiatric Association [APA], 2000, p. 456). Chronic social anxiety may result in continued isolation and avoidance of social situations. Moreover, physiological arousal and heightened somatic responding has been associated with high levels of social anxiety in children (Beidel, Turner, \& Dancu, 1985; Beidel, Christ, \& Long, 1991). 
The role that social anxiety plays in Internet use is intriguing as social relationships are rapidly expanding into an online forum. This is particularly apparent with social networking sites as increasing numbers of adolescents are using them to communicate regularly with peers (Lenhart \& Madden, 2007). While the rates of social networking site use continues to increase across all age groups, it is less clear as to the types of people who benefit most from its use.

In their research on sociability and Internet use, Zywica and Danowski (2008) concluded that, "Social networking websites are widely thought to have changed students' communication patterns and how they perceive themselves and their peers both online and offline" (p. 3). Because the social lives of many individuals have an online component, these authors believed that it is crucial to understand a person's self-presentation, how it impacts online status, and how psychological variables may be associated with online and offline popularity. Similarly, Joinson (2003) maintains that self protection, self-enhancement, and self-esteem play a major role in why people use the Internet to communicate.

The use of self perception concepts, such as self-esteem, may be problematic in research involving social networking websites for several reasons. First, the construct of self-esteem remains loose and vague as no consistent definition exists in the literature. For example, Pope, McHale, and Craighead (1988) defined self-esteem as a construct that assesses the information resulting from the discrepancy between one's perceived and real self. Frey and Carlock (1989) associated self-esteem with the subscales of competence and worthiness. Moreover, Mruk (1999) conceptualized self-esteem in terms of competent or effective behavior. Finally, Tafarodi and Ho (2006) identified self-esteem as a measure of one's personal worth with a specific identity. The aforementioned examples represent only a small sample of the overall pool of varying definitions that have been associated with self-esteem. 
Another problem associated with the use of self-esteem is the poor quality of available instruments that are currently used to assess the construct (Kohn, 1994; Marsh \& Holmes, 1990; Wylie, 1989). Kaplan (1995) concluded: "I suspect that research studies on self-esteem would be strongly criticized for their lack of construct validity, because no two investigators define, or use instruments that define, self-esteem the same way" (p. 341). While recent efforts have attempted to unify and adequately assess the construct, a clear consensus continues to elude supporters of self-esteem.

A third problem with a reliance on self-esteem as a construct is the lack of a link between increasing self-esteem and an improvement in treatment outcome. London (1997) found no evidence that supported an association of high self-esteem and mental health. Furthermore, Kaplan (1995) was unable to find any direct relationship between self-esteem and problems that many educators, counselors, and members of the popular press have typically associated with low self-esteem (e.g. school failure, drug and alcohol abuse, crime, and welfare dependency).

In contrast, social anxiety, a much more stable construct, has been studied extensively in the literature with respect to adolescent online behavior. Several competing hypotheses have been formulated in order to explain why adolescents of varying levels of anxiety use the Internet to communicate with their peers. The Social Compensation Hypothesis maintains that selfprotective individuals tend to be more introverted and socially anxious, and that these individuals are more likely to use the Internet to substitute online relationships for undesirable offline social networks (Valkenburg, Schouten, \& Peter, 2005). On the other hand, the Social Enhancement hypothesis proposes that individuals who are extroverted and are less socially anxious are motivated to add friends online to their existing large network of offline friends (Peter, Valkenburg, \& Schouten, 2005; Kraut et al., 2002; Walther, 1996). 
Currently, there is no consistent conclusion with respect to the role that social anxiety may play on an individual's use of the Internet. Papacharissi and Rubin (2000) found that Internet users who were socially anxious and avoided face-to-face interaction chose the Internet as a functional alternative channel. Others have concluded that the Internet provides a form of mass communication in which one can conceal their appearance thus minimizing much of the social risk associated with a meeting offline (Curtis, 1997; Stevens \& Morris, 2007). Moreover, anxiety reduction was found to be the primary purpose for college students pursuing an online romantic relationship (Knox, Daniels, Sturdivant, \& Zusman, 2001). Similarly, Ward and Tracey (2004) concluded that highly shy individuals were more likely to pursue relationships online. Finally, socially anxious adults were more likely to form relationships online and these relationships tended to progress much faster than offline relationships (McKenna \& Bargh, 2000).

On the contrary, other studies have contradicted these findings. For example, Ma and Leung (2005) found that people who are less willing to communicate in real life also tend to be less open online. In addition, researchers have found that people who form relationships online tend to exhibit similar social skill compared to those who do not form online relationships (McCown, Fischer, Page, \& Homant, 2001). Stevens and Morris (2007) examined the association between social and dating anxiety and Internet use and identified specific media that people of high and low social anxiety may use when starting and maintaining relationships. They found that young adults who reported having low social anxiety used Internet blogs significantly more often than people who had high social anxiety. On the other hand, highly socially anxious young adults were nearly nine times more likely to use web cameras than people who reported low social anxiety. 
Overall, these findings demonstrate the inconsistencies that exist in the literature pertaining to the association between social anxiety and Internet use. While the literature on this subject is rather limited, there are even fewer studies involving social anxiety that focus on social networking websites especially with adolescent populations.

Acar (2008) studied the association between anxiety, as measured by the Spielberg StateTrait Anxiety Inventory Scale, and the time spent on a social network website. He was also interested in investigating whether or not people who have a large amount of online friends have higher or lower levels of anxiety than people who have a small amount of online friends. The study included a sample of 451 (223 males, 228 females) young adults who were enrolled in an introductory-level communications course at a college in the northeast region of the United States. Using time spent on a social networking website and social network size as predictors and anxiety as the dependent variable, a multiple regression equation suggested that there was no significant relationship between anxiety and the amount of time a college student spent on a social network website or the size of a college student's online social network.

In another study investigating anxiety and undergraduate use of Facebook, Sheldon (2008) demonstrated that participants who feel anxiety and fears when communicating in person generally logged on to Facebook to pass time when they were bored or to feel less lonely; however, these people tended to have fewer Facebook friends. The types of people who are involved with online relationships through social networking websites tended to be those who were willing to communicate in real life rather than the opposite. These results supported previous assumptions that the Internet tends to benefit extraverted individuals (Kraut, Kiesler, Boneva, \& Cummings, 2002) and that introverts communicate online less often (Peter et al., 2005). 


\section{Parenting Factors}

In addition to social anxiety, another important factor that may be related to adolescent use of the Internet is parenting. Specifically, parental monitoring has been found by researchers to be an important intervention when predicting positive adolescent adjustment (Frojd, KaltialaNeino, \& Rimpela, 2007; Sagrestano, Holmbeck, Paikoff, \& Fendrich, 2003). It is defined as “a set of strategies used to gain knowledge about an adolescent's whereabouts, their friends and associates, and their activities (National Institute on Drug Abuse, 2002). Other similar definitions have incorporated direct supervision, knowledge of the child's whereabouts, communication between the parent and child, and rules about the child's activities (Racz \& McMahon, 2011). Stattin and Kerr (2000) concluded that parental knowledge about their adolescent's life may be obtained through parent-driven behaviors (solicitation and control) and child-driven behaviors (self-disclosure). With respect to the parent-driven behaviors, solicitation refers to the parent asking the child directly and control is based on establishing firm rules and restrictions. These behaviors are generally believed to belong to the set of behaviors known as parental monitoring. On the other hand, self-disclosure involves the spontaneous sharing of truthful information by the adolescent.

The research literature is mixed with respect to which approach is most effective in producing parental knowledge. For example, Kerr and Stattin (2000) demonstrated that parental knowledge was most strongly associated with adolescent self-disclosure compared to solicitation or control. In addition, researchers found that more self-disclosure was associated with less delinquent behavior and that more delinquent behavior predicted less disclosure (Keijsers, Branje, VanderValk, \& Meeus, 2009; Kerr, Stattin, \& Burk, 2010). Conversely Fletcher, Steinberg, and Williams-Wheeler (2004) found that parental control and solicitation can lead to a 
reduced likelihood that children will engage in conduct problems. Increased parental monitoring has also been associated with a reduction in adolescents' susceptibility to depressive symptoms (Jacobson \& Crockett, 2000; Kim \& Ge, 2000; Sagrestano, Holmbeck, Paikoff, \& Fendrich, 2003) as well as a reduction in adolescent sexual risk behavior (Li, Stanton, \& Feigelman, 2000; Rose et al., 2005). Finally, higher levels of parental monitoring have been found to predict lower odds of drug initiation and use (Chilcoat \& Anthony, 1996; Diclemente et al., 2001).

To date, there is little research that examines associations among parental monitoring behaviors and adolescents' corresponding online behavior. The Pew Internet and American Life Project (MacGill, 2007) reported that a majority of parents try to be involved in their child's online activity. For example, $65 \%$ of parents reported they regularly check the websites their teen visits, and $74 \%$ claim that they know whether or not their teen has created a social networking website profile. Furthermore, $85 \%$ of parents reported that they have established specific guidelines as to what kinds of personal information their child can disclose to other people over the Internet; however, it is unclear how many parents actually follow up on these rules. Liau, Khoo, and Ang (2008) demonstrated that parents tend to overestimate the amount of parental monitoring that they engage in and underestimate their adolescents' engagement in risky online behaviors. In addition, they found that mothers had greater knowledge of their adolescents' Internet use compared to fathers

\section{Parenting Style}

Diana Baumrind (1967) conceptualized parenting along three distinct styles: authoritative, authoritarian, and permissive parenting. She identified authoritative parenting as the incorporation of disciplined conformity and child autonomy in which the parent directs the child's behavior in a rational manner. Authoritarian parenting emphasizes strict obedience to a 
higher authority in order to shape and control the child's behavior, thus limiting his or her autonomy. Finally, permissive parenting involves non-punitive action by the parent in which the child is given increased autonomy and obeying rules is not prioritized. Parenting style has also been characterized and assessed in terms of the presence or absence of warmth and care as well as overprotection and control (Parker, Tupling, \& Brown, 1979)

Research has demonstrated an association between parenting behavior and infantcaregiver attachment styles. For example, three specific patterns of attachment (secure, insecureambivalent, and insecure-avoidant) were identified by Ainsworh, Blehar, Waters, \& Wall (1978) using the "Strange Situation"; a task that involved the observation of an infant's reaction to repeated separations and reunions with the caregiver. Furthermore, childhood anxiety has been associated with parents who demonstrate high levels of overprotection and control and limited displays of care and warmth (Duggan, Sham, Minne, Lee, \& Murray, 1998; Wiborg \& Dahl, 1997). For instance, Krohne and Hock (1991) found that mothers of highly anxious girls were more controlling than mothers of girls with low anxiety when they were observed working together on a puzzle task. Moreover, Greco and Morris (2002) observed father-child dyads and found that fathers of children with high levels of anxiety were more controlling than fathers of children with low social anxiety when working on an origami task.

More recently, research has focused on how parenting style has mediated their child's Internet use. For example, Eastin, Greenberg, and Hofschire (2006) examined how parents mediated Internet use and found that parents who used evaluative and restrictive techniques were more likely to employ an Authoritative parenting style (high control; high warmth) in contrast to an Authoritarian (high control; low warmth) or a Neglectful (low control; low warmth) parenting style. In addition, Authoritative parents were more likely to use software that blocks 
inappropriate content compared to Authoritarian or Neglectful parents. Finally, parental monitoring, a key characteristic of an Authoritative parenting style, was found at higher levels among parents of younger teenagers compared to parents of older teenagers (Wang, Bianchi, \& Raley, 2005).

Researchers are beginning to explore the relationship between parenting and adolescent use of social networking websites like Facebook. In one such study, Rosen, Cheever, and Carrier (2008) examined the association among parenting style, limits that were set, and adolescent use of MySpace. They found that Authoritative parenting style was related to the teenager engaging in fewer high-risk behaviors. Examples of these "high risk" behaviors include disclosing any kind of personal information and low likelihood of meeting online "friends" in person. This corroborates the findings of Eastin, Greenberg, and Hofschire (2006) which showed that Authoritative parents were more likely to intervene when it comes to their teenager's use of various media. Rosen et al. (2008) also found that the parents did not show a high level of Internet monitoring and limit setting with respect to teen online behavior. Furthermore, parents were generally unaware of their adolescent's online activity on MySpace. In particular, there was a large discrepancy between the teens' disclosure of personal information and their parent's perception of the disclosure where parents greatly underestimated the actual amount of disclosure. The authors concluded that parents tended to greatly underestimate the amount of information their teenager was disclosing. In addition, the authors found that an Authoritative parenting style was associated with a parent's child engaging in fewer risky online behaviors (e.g. disclosure of personal information, meeting an online acquaintance in person).

Other studies are now emerging that examine the role that parenting factors play in their child's Internet use. For example, Valcke et al. (2010) found that an Authoritarian parenting style 
was associated with very low Internet usage among children while a Permissive parenting style was associated with very high usage with this population. These authors also observed more parental monitoring and control in younger children compared to teenagers. In addition, Livingstone and Helsper (2008) found that parents with greater experience in using the Internet engaged in greater mediation of their child's Internet use. They also identified characteristics of adolescents that were associated with risky online behavior (e.g. violence, pornographic, privacy, contact). Specific predictors of online risk included being older, having greater online skills, and being male.

\section{Present Study}

Few studies exist in the literature that attempt to identify the types of factors, such as social anxiety, that are associated with the use of social networking websites such as Facebook. Moreover, most of the existing research has neglected adolescent populations and instead has focused solely on undergraduates and young adults. Also, there is limited research that examines specific parenting factors and adolescent use of social networking websites. Furthermore, there have not been any studies to date that have examined social anxiety and parenting variables and their relation with adolescent use of Facebook. These studies are critical because little is known about the characteristics of people who use Facebook especially in a population associated with high risk behavior like adolescence.

The present study was designed to examine level of social anxiety and Facebook use in a high school sample of adolescents. Another goal of this study was to examine the association between adolescent Facebook use and parenting factors, such as parental limit setting and monitoring, parental care, and parental control.

\section{Research Questions and Hypotheses}




\section{Research Question 1}

Do socially anxious adolescents behave differently on Facebook compared to their less socially anxious peers?

Hypothesis 1: Use of Facebook will differ for adolescents by level of social anxiety. H1A: The proportion of adolescents who have an active Facebook account will be higher among those with low social anxiety (SPAI score $\leq 34)$ than those who report high social anxiety (SPAI score $\geq 60$ ).

H1B: Among those who have an active Facebook account, the proportion of adolescents who use Facebook to maintain existing friendships (rather than attempt to make new friends) will be higher among those with low social anxiety than those who report high social anxiety.

H1C: Scores on the SPAI will be inversely associated with number of friends and amount of time spent on Facebook.

\section{Research Question 2}

Is parental control, as reported by the adolescent, associated with social anxiety?

Hypothesis 2: More parental control will be directly associated with higher social anxiety.

\section{Research Question 3}

Do mothers and fathers behave differently with respect to parental control, monitoring, and limit setting?

Hypothesis 3: Parenting variables will differ for mothers versus fathers.

H3A: Fathers will engage in higher levels of parental control and limit setting than will mothers. 
H3B: Mothers will engage in higher levels of parental monitoring than will fathers.

\section{Research Question 4}

What parenting factors will predict adolescent risky online behavior?

Hypothesis 4: More parental monitoring, parental limit setting, and parental control will predict less risky online behavior within Facebook.

\section{Method}

\section{Participants}

A total of 193 adolescents and 253 parental guardians participated in this study. In the adolescent sample, data from 31 participants were completely deleted from the dataset due to the adolescent being too young (under 16 years-old) or having not completed the online survey. The final sample used in the study analyses included 162 adolescents and 192 parental guardians who for the remainder of this document will be referred to as mothers and fathers.

The adolescent sample was comprised of 102 males, and 60 females. Caucasians represented $95 \%$ of the adolescent participants followed by $4 \%$ Black and less than $1 \%$ American Indian. In addition, 3\% of the participants identified their ethnicity as Hispanic. The age of the adolescent participants consisted of 16,17 , and 18 -year-olds representing $31 \%, 44 \%$, and $25 \%$ of the sample respectively. With respect to parent participants, 142 were female and 50 were male. Furthermore, the majority of female parents were biological mothers $(98 \%)$ while $94 \%$ of the male parent participants were biological fathers.

Survey data was collected from at least one parent, and attempts were made to obtain information from both the mother and the father in order to evaluate differences in parent report. Survey questionnaires did not specifically address whether the adolescent was living in a one or 
two-parent household; however, two adolescent participants were unable to answer questionnaire items about their fathers due to having no communication with him. Adolescent participants were not required to have a Facebook account; however, they had to have access to the Internet. Finally, all participants were English speaking.

\section{Parent-Report Measures}

Demographic Information: Participants were instructed to report on basic demographic information such as age, gender, and race/ethnicity (see Appendix A).

Parental Knowledge of Adolescent Facebook Use Questionnaire (PFQ; Appendix B): This questionnaire is a parent-report instrument that was created to collect data about a parent's knowledge of his or her child's use of Facebook. Information that was collected included the number of times their child logs in to Facebook, the amount of time their child utilizes the website, the number of friends their child has accepted on his or her profile page, and the number of social networking websites outside of Facebook that their child belongs to (e.g. MySpace, Twitter, etc.). In addition, parents were asked what types of limits if any are in place for their children when using Facebook. Parents of adolescents were also asked several questions pertaining to the kind of information that their child discloses on Facebook. This included disclosure of personal contact information, message content, and the kinds of pictures that are posted.

The Parent Limit Setting and Monitoring Scale - Parent Version (PLMS-P; Healy, 2004; Appendix C): The PLMS-P is a report of the extent to which a parent sets limits and monitors his or her teenager's online behavior. The scale contains 12 items, based on a factor analysis of 24 original items, and each item requires the respondent to answer using a five-point scale (0-never to 4-always). For example, one item reads: "I know what my teenager is doing at 
all times”. Rosen et al. (2008) found alpha coefficients of .90 and .92 for parent and adolescent samples respectively. In the same study, scores of parent and adolescent report on the PLMS were significantly correlated $(r=.75)$.

\section{Adolescent-Report Measures}

Social Phobia and Anxiety Inventory (SPAI; Turner, Beidel, Dancu, \& Stanley, 1989; Turner, Beidel, \& Dancu, 1996). The SPAI was used to assess anxiety that adolescents may be experiencing in various social situations. The instrument consists of 45 multipart items rated on a scale from 0 (never) to 7 (always). Psychometric properties of the SPAI have been assessed using clinical and nonclinical samples. Preliminary evaluation of the measure among college students indicated high internal consistency (.96) and test-retest reliability $(r=.86)$ over a 2week period (Turner, Beidel, \& Stanley, 1989). The SPAI has also been found to demonstrate the ability to discriminate individuals diagnosed with social phobia from other clinical (panic disorder, agoraphobia, obsessive compulsive disorder) and nonclinical populations (Turner, Beidel, Dancu, \& Stanley, 1989; Turner, Beidel, Stanley, \& Bond, 1989). In addition, the SPAI has demonstrated external validity through the use of diary ratings of distress and behavioral avoidance (Beidel, Borden, Turner, \& Jacob, 1989; Beidel, Turner, Stanley, \& Dancu, 1989). When compared to other self-report measures of social anxiety with respect to diagnostic sensitivity, specificity, and discriminant validity, results suggest that the SPAI is superior (Herbert, Bellack, \& Hope, 1991; Mattick \& Clarke, 1998; Peters, 2000; Turner et al., 1996). Moreover, the SPAI has demonstrated superior utility as a measure of treatment change (Beidel, Turner, \& Cooley, 1993).

The SPAI is intended for use with individuals ages 14 and older. When used with adolescent samples, the SPAI has demonstrated higher internal consistency (.97), construct 
validity, and ability to discriminate adolescents with social phobia from those with other diagnoses (Clark et al., 1994). In particular, the study conducted by Clark et al. (1994) included 223 adolescents between the ages of 12 and 18 years who were recruited from clinical and community sources. There were no effects for age in this study; however, total SPAI scores were higher for girls than for boys, and this is consistent with other research on anxiety. More recently, Olivares, Garcia-Lopez, Hidalgo, \& Caballo (2004) conducted a study in Spain using a Spanish speaking sample of 303 adolescents (202 with social phobia) and demonstrated concurrent validity of the SPAI with the Social Anxiety Scale for Adolescents (SAS-A).

Adolescent Facebook Use Questionnaire (AFQ; Appendix D): This questionnaire is a self-report instrument that was created for this dissertation investigation to collect data pertaining to an adolescent's use of Facebook. Information that was collected included the number of times the user logs in to Facebook, the amount of time the user utilizes the website, the number of friends the user has accepted on his profile page, and the types of social networking websites outside of Facebook that the user belongs to (e.g. MySpace, Twitter, etc.). Additional information regarding the adolescent's behavior while he or she is logged on to Facebook was also collected. This included the amount of time the user devotes to posting pictures, adding friends, browsing other profiles, editing a profile, writing public comments, sending personal messages, and joining a group. In addition, adolescents answered a series of questions pertaining to why they use Facebook. Answer choices included: to maintain existing friendships, to make new friends, to keep in touch with friends that are rarely ever seen, to find a romantic relationship, to avoid boredom, or to express one's opinion on various issues. Finally, adolescents were asked several questions pertaining to the kind of information that they disclose 
on Facebook. Answers included disclosure of personal contact information, message content, and the kinds of pictures that are posted.

Parental Bonding Instrument (PBI; Parker, Tupling, \& Brown, 1979; Appendix E).

The PBI was initially developed as a 25 -item retrospective questionnaire assessing perceptions of care (warmth) and overprotection (control) exhibited by each parent during the individual's first 16 years. A number of psychometric studies suggest that the PBI has demonstrated good reliability and validity. Parker et al. (1979) found that the PBI had very good internal consistency and test-retest reliability. Parker (1983) also found that the PBI has been shown to demonstrate satisfactory construct and convergent validity when using between-subject sibling corroborative reports. In addition, corroborations of parenting behavior were demonstrated using monozygotic and dizygotic twin report of parent behavior resulting in high correlations between sibling reports (Mackinnon, Henderson, \& Andrews, 1991; Parker, 1986). Subsequent research has been conducted with a version designed to measure children's current perceptions of their parents' behavior (Greco \& Morris, 2002). The revised form represents only minor modifications from the original; specifically, items were phrased in the present tense and double negatives were reworded in the affirmative so as to be less confusing. The present-tense version was used in the current investigation.

\section{The Parent Limit Setting and Monitoring Scale - Adolescent Version (PLMS-A;}

Healy, 2004; Appendix F): The PLMS-A is an adolescent's report of the extent to which his or her parent sets limits and monitors the teenager's online behavior. The scale contains 12 items, based on a factor analysis of 24 original items, and each item requires the respondent to answer using a five-point scale (0-never to 4-always). A sample item states, "My parent knows what I am doing at all times". 


\section{Procedure}

Adolescents and parents were recruited for the study using ads that were distributed by email, in high school classrooms, or in person at high school athletic events. To compensate them for their time, all participants were entered into a drawing to receive a cash prize in the amount of $\$ 500, \$ 250$, or $\$ 100$, and participants who were recruited at high school athletic events received a professionally produced DVD of the event.

Parents who were interested in participating in the study were contacted by the investigator by phone or e-mail. The mother or father was then provided with a detailed description of the study as well as information regarding the consent and assent process for the parent and adolescent. Parent participants were then sent an e-mail that contained a user login and password to a web-based survey service called SurveyMonkey. Before beginning the survey questionnaires, online consent forms to participate in the study were completed by the parent. Once the parent was finished, an online assent form was sent to the adolescent. After assenting to participate, the adolescent completed the survey questionnaires. Parents and adolescents were instructed to complete the measures separately so that they would not influence each other's' answers. The surveys took approximately 30 minutes for the adolescent to complete and 20 minutes for the parent to complete. User responses included Secure Sockets Layer (SSL) encryption ensuring maximum protection from breeches of disclosure of confidential information.

\section{Results}

\section{Preliminary Analyses}

Adolescent Gender Differences. Descriptive statistics for the adolescent report measures are included in Table 1. Independent samples T-tests were undertaken to examine possible 
gender differences for adolescent-reported social anxiety (SPAI), parenting style (PBI), online parental limit setting and monitoring (PLMS-A). The mean SPAI score for the entire adolescent sample was $38.50(S D=26.98)$ and there was no significant difference in SPAI scores for female and male adolescent participants.

Adolescents reported parenting style for both parents along the two constructs of Parental Care and Parental Control. Parental Care scores had a possible range of 0-39 with high scores being associated with more care. Maternal Care scores did not differ significantly by gender of adolescent informant (sons/daughters). Similarly, there was no significant difference between sons and daughters' ratings of Paternal Care. Parental Control scores had a possible range of 036 with higher scores being associated with more control. There was no significant difference in maternal scores for sons and daughters; however, daughters reported significantly higher Paternal Control compared to sons (see Hypothesis 3A).

Adolescents reported parental limit setting and monitoring for each parent using the PLMS-A. The PLMS-A yielded two subscales and a total score and each average score had range of 1-5. As shown in Table 1, there were no significant differences when comparing daughters and sons ratings of each of their parents on the total score as well as the parental monitoring and parental limit setting subscales.

Parental Differences. Independent samples T-tests were conducted to examine possible differences between the PLMS-P and its subscales. The PLMS-P yielded two subscales and a total score; each score was an average of the scale's items with a possible range of 1-5. As shown on Table 2, mothers had significantly higher total scores than fathers; $t(173)=2.62, p=$ .01 . With respect to the parental monitoring scale, mothers engaged in significantly more 
monitoring than fathers; $t(173)=3.67, p<.01$. Mothers and fathers did not differ significantly with respect to self-reported limit setting.

Correspondence between adolescent and parent reported items was evaluated using Pearson product moment correlations. As shown in Table 3, correlation coefficients ranged from low to moderate. The highest correspondence between adolescents and mothers was found with respect to: the mother corresponding with parents of friends (Item $1 ; r=.5$ ) and the mother setting limits on the amount of time the adolescent spends on Facebook (Item $9 ; r=.47$ ). Furthermore, the highest correspondence between adolescents and fathers was found with respect to: the father knowing how the adolescent spends his/her money (Item $6 ; r=.56$ ) and the adolescent contacting the father if his/her plans change (Item $7 ; r=.56$ ).

Facebook Usage. The Adolescent Facebook Questionnaire included specific questions pertaining to how adolescents use Facebook. As shown in Table 4, 91\% of adolescents reported that they have an active Facebook account with a higher percentage of females having an account (97\%) than males (87\%). The Parent Facebook Questionnaire included specific questions pertaining to how parents use Facebook as well as how the parent thinks his or her adolescent uses Facebook. Similar to the adolescent report, 91\% of parents reported that their child has an active Facebook account, $8 \%$ said they did not, and 1\% said they did not know. Only five parents out of $192(<3 \%)$ were incorrect about knowing if their child had a Facebook account. Interestingly, four of these parents thought their child had a Facebook account when they did not. Only one mother indicated that her son was not on Facebook when in fact he was. Finally, $62 \%$ of parents reported that they have an active Facebook account with a higher percentage of mothers having an account (70\%) than fathers $(36 \%)$.

\section{Tests of Hypotheses}




\section{Hypothesis 1: Use of Facebook will differ for adolescents by level of social anxiety.}

Hypothesis 1A stated that the proportion of adolescents who have an active Facebook account will be higher for those who reported low social anxiety compared to those who reported high social anxiety. Adolescent participants were grouped into high and low social anxiety groups using the cut off scores determined by the test developers. Forty-two adolescents had a score of 60 or higher and were grouped into the high social anxiety group, and 74 adolescents had a score of less than or equal to 34 and were grouped into the low social anxiety group. Moreover, $92 \%$ of the adolescents in the high social anxiety group had an active Facebook account while only $8 \%$ reported that they did not. Similarly, $91 \%$ of adolescents in the low social anxiety group had an active Facebook account while 9\% did not. The Chi-squared test for independence (with Fisher's Exact Test) indicated no significant association, $\chi^{2}(1, n=116)=0$, $p=1.0, \mathrm{phi}=.02$. Thus, these results revealed that adolescents in the high social anxiety group were just as likely to have a Facebook account as those in the low social anxiety group. Hypothesis 1B stated that the proportion of adolescents who use Facebook to maintain existing friendships will be higher among those with low social anxiety than those in the high social anxiety group. One hundred and six adolescents participants who use Facebook were classified as either having high or low social anxiety. Of these, 101 used Facebook to maintain existing friendships while only five used Facebook to meet new people. The Chi-square test for independence (with Fisher's Exact Test) indicated no significant association, $\chi^{2}(1, n=106)=0$, $p=1.0$, phi $=-.02 .$, providing no support for the hypothesis that the proportion of adolescents who use Facebook to maintain existing friendships will be higher among those in the low social anxiety group compared to those in the high social anxiety group. Hypothesis $1 \mathrm{C}$ stated that scores on the SPAI will be inversely associated with the amount of time spent and number of 
friends on Facebook. This hypothesis was tested by conducting Pearson product moment correlations. Results indicated that the time spent on Facebook was not significantly related to social anxiety ( $r=-.01, p=.93)$; providing no support for the hypothesis that higher social anxiety will be related to lower amount of time spent on Facebook. However, a significant inverse correlation was observed between number of friends on Facebook and social anxiety $(r=$ $-.20, p<.05)$. A follow-up analysis was conducted using a Chi-square test for independence in which 99 adolescent participants were classified based on the number of friends they had on Facebook. The low group consisted of adolescents with fewer than 100 friends while the high group consisted of adolescents with more than 200 friends. Adolescents were also classified into high and low social anxiety groups using the cut off scores determined by the test developers. A Chi-Square test for independence (with Fisher's Exact Test) indicated a significance association, $\chi^{2}(1, n=99)=7.52, p<.01, \mathrm{phi}=-.31$. These results revealed that the proportion of adolescents who have more friends on Facebook was higher among those in the low social anxiety group compared to those who reported high social anxiety, thus providing partial support that having a lot of friends on Facebook is associated with lower social anxiety.

Hypothesis 2: Parental control will be directly associated with social anxiety. The second hypothesis that parental control would be related to social anxiety was tested using Pearson product moment correlations. A significant correlation was observed between social anxiety and parental control for mothers $(r=.20, p=.01)$ and parental control for fathers $(r=$ $.18, p=.04)$. Based on Cohen's (1988) guidelines, this would be classified as a small correlation and suggests some support for the hypothesis that more controlling parents have children who are more socially anxious. 


\section{Hypothesis 3: Parenting variables will differ for mothers versus fathers. The}

hypothesis that adolescent report of mothers and fathers would differ on measures of parental control and limit setting (Hypothesis $3 \mathrm{~A}$ ) as well as on parental monitoring (Hypothesis $3 \mathrm{~B}$ ) was examined by conducting independent samples T-tests (see Table 5). With respect to parental control, there was no significant difference in adolescent report of maternal and paternal control; however, additional analyses were conducted in which adolescent report of maternal and paternal control was analyzed separately across gender. A follow-up T-test revealed significantly higher paternal control as reported by daughters $(M=12.80, S D=7.31)$ compared to sons $(M=10.05$, $S D=5.30) ; t(96)=2.54, p=.01$. The magnitude of the differences in means (mean difference $=$ 2.75, CI: .77 to 4.73$)$ was small to moderate $(\eta=.04)$. With respect to parental limit setting, there was a significant difference for adolescent report of mothers $(M=2.78, S D=.82)$ compared to fathers $(M=2.52, S D=.82 ; t(284)=2.65, p<.01$. The magnitude of the differences in means (mean difference $=.26,95 \%$ CI: .07 to .45$)$ was small $(\eta=.02)$. Moreover, there was a significant difference in measures of parental monitoring for mothers $(M=3.76, S D=.74)$ and fathers $(M=3.21, S D=.93) ; t(270)=5.56, p<.001$. The magnitude of the differences in means (mean difference $=.55,95 \% \mathrm{CI}: .35$ to .75$)$ was moderate $(\eta=.10)$.

\section{Hypothesis 4: Parenting variables will predict risky online behavior within}

Facebook. The hypothesis that parental control, parental monitoring, and parental limit setting will predict risky online behavior on Facebook was tested using a standard multiple regression analysis. A risky online behavior composite variable was computed by summing the responses of items 15-18 on the Adolescent Facebook questionnaire. These were dichotomous items that asked about posting photos of alcohol and drug use (item 15), posting sexual photos (item 16), posting foul language (item 17), and adding friends that one has never met in person (item 18). 
Risky online behavior scores could range from 0 (no risky online behavior) to 4 (high risky online behavior).

Prior to evaluating the model, the data were inspected to make sure specific assumptions were met. First, potential outliers were detected by inspecting the Mahalanobis Distance values provided in the output. There were three cases that exceeded the critical value of 22.46 suggested by Tabacknik and Fidell (1996) and these cases were omitted from the analyses.

Multicollinearity was assessed using a correlation matrix of the independent variables entered into the equation to ensure that correlations between the variables were not too high. The correlation for parental limit setting (mother) and parental limit setting (father) was high $(r=.86$ $, p<.01)$ which is more than the cut-off of .7 suggested by Pallant (2007). Multicollinearity was also assessed by observing the tolerance values in the output. A tolerance value less than .10 indicates that there is high correlation with other variables suggesting the presence of multicollinearity. The tolerance values for mother and father parental limit setting were .16 and .13 respectively. Although both values exceeded the cut-off of .10, the father parental limit setting variable was removed from the multiple regression equation given its high correlation with mother parental limit setting. Finally, an inspection of the Normal Probability Plot of the Regression Standardized Residual revealed no major deviations from normality.

A standard multiple regression model using mother overprotection, father overprotection, mother parental monitoring, father parental monitoring, and mother parental limit setting to predict adolescent risky online behavior was conducted. Results indicated that the predictor variables in the model did not account for a significant proportion of variance in risky online behavior, $R^{2}=.07, F(5,131)=1.97, p=.09$. Parental monitoring by fathers made the strongest unique contribution to explaining adolescent risky online behavior $(\beta=-.20, p=.08)$; however, 
in terms of the overall variance, it explains a very small percentage. Squaring the semi-partial correlation coefficient (-.15) demonstrates that only $2 \%$ of the total variance in adolescent risky online behavior is uniquely explained by father parental monitoring.

\section{Exploratory Analyses}

Depression. Adolescent self-report of depression was modestly correlated with social anxiety $(r=.21, p=.01)$ as well paternal control $(r=.18, p=.02)$ but was not significant for maternal control. Moreover, adolescents who reported mild to severe depressive symptoms were just as likely to have an active Facebook account as those with minimal depressive symptoms. Moreover, depression was not associated with adolescents engaging in risky online behavior (e.g. posting sexually suggestive pictures or alcohol/drug use photos, using foul language, accepting strangers as friends).

Facebook Usage. An overwhelming majority of the sample (95\%) indicated that they use Facebook to communicate with existing friends as opposed to meeting new people. More than half the sample reported that they log on to Facebook at least once a day (54\%) with 28\% admitting that they $\log$ on more than once a day (see Table 6). Moreover, $66 \%$ of the sample reported that they spent less than 30 minutes on Facebook each time they logged on and 33\% spent less than 15 minutes with each login. As seen in Table 7, these percentages are consistent across gender. The total number of friends on an adolescent's Facebook profile was assessed using increasing intervals. A large majority of the sample (80\%) reported that they had more than 200 friends with 44\% reporting that they had over 400 (See Table 8). On the other hand, only 5\% of the sample reported that they had fewer than 50 friends on their Facebook profile.

Information Disclosed. Adolescents varied with respect to the type of information that they disclosed on their Facebook profile. Sixty-nine percent of adolescents disclosed their full name, $46 \%$ disclosed their e-mail address, $75 \%$ disclosed their school name, $31 \%$ disclosed their 
phone number, and 18\% disclosed their home address. As seen on Table 9, these percentages are similar across gender. Parents were also asked about the information that their adolescent discloses on Facebook and a higher percentage of mothers compared to fathers knew about specific information that was being disclosed. Furthermore, nearly one-third of the father sample reported that they did not know any kind of information was being disclosed on their child's Facebook page (compared to $8-15 \%$ of mothers who did not know).

Risky Online Behavior. Items 15-18 on the AFQ addressed risky online behavior with respect to the type of information that an adolescent posts on his or her Facebook profile. Less than $5 \%$ of the sample reported that they have posted photos involving drug or alcohol use and less than $3 \%$ responded that they had posted sexually suggestive photos of themselves or their friends. Moreover, $15 \%$ of the sample reported that they had posted foul or sexually suggestive language on their Facebook page. A majority of the sample (61\%) admitted that they have added friends to their Facebook profile whom they have never met offline.

Parents also reported their knowledge of adolescent risky online behavior (see Table 10). Many of the parent participants (between 5\% and 26\% depending on the behavior) indicated that they did not know what their teenagers were doing on Facebook. The Kappa correlation coefficient was used to measure agreement between the adolescent and parent report for each of the four risky online behavior items on the AFQ. The level of agreement for each item was: .23 for posting photos involving drug or alcohol use, .33 for posting sexual photos, .43 for posting foul or sexually suggestive language, and .08 for adding strangers to their Facebook profile.

Privacy Settings. Adolescents also varied in the privacy settings that they set on their Facebook profile. Four percent of the sample set the most stringent settings (even friends have limited access), 70\% only allow their friends to have access, $11 \%$ allow friends of their friends, 
$5 \%$ allow people in their network, and 9\% allow everyone to have access to their Facebook profile. As seen in Table 11, a higher percentage of females had more stringent privacy settings while more males had the least restrictive settings which allowed everyone to have access.

Parental Monitoring of Facebook. The rate at which parents monitored their adolescent's Facebook account was reported by adolescent and parent participants. Nearly $52 \%$ of adolescents reported that their mother monitors their Facebook page at least once a week while only around $23 \%$ of adolescents reported the same for their father. Furthermore, only about $20 \%$ of adolescents reported that their mother has never checked their Facebook page while over $60 \%$ of adolescents reported that their father has never checked out their page. These trends suggest that an inverse relationship exists between the amount of monitoring mothers and fathers are engaging in and this trend is also consistent across parent report (see Table 12).

Seventy-two percent of adolescents reported that their mother allows them to have a computer with Internet access in their bedroom and this rate drops slightly to $68 \%$ when asked if their father allows the same privilege. Interestingly, $81 \%$ of daughters reported that their mothers allowed them to have a computer in the bedroom compared to $66 \%$ of sons who reported that they were allowed this privilege. This trend was similar but smaller for fathers with $74 \%$ of daughters reporting a computer in the bedroom compared to $64 \%$ of sons. There was no association between having a computer in the bedroom and engaging in risky online behavior. Finally, $86 \%$ of adolescents reported that that their mother has talked to them about the potential problems related to online communication while about $70 \%$ of fathers have addressed this issue.

Engaging in Other Activities. When asked about using other social networking websites, $42 \%$ of adolescents said they use MySpace, $27 \%$ use Twitter, and less than $8 \%$ use other websites (e.g. AIM, Formspring, MyYearbook, Skype, Tumblr). Adolescents also indicated 
other types of activities that they engaged in outside of Facebook use. Sixty-seven percent of the sample reported that they engage in sports every day, and $22 \%$ reported that they play sports several times a week. Only $10 \%$ of the sample reported that they do not play sports at all, but this is expected given that a majority of the participant sample was recruited from high school athletic events. Contrarily, about $71 \%$ of the sample reported that they never play musical instruments while nearly $14 \%$ reported playing an instrument every day, $7 \%$ play several times a week, and 9\% play only about once a week. Adolescent rates of participation in other activities such as spending time outdoors, working in the church, spending time in academic clubs, spending time in school clubs, volunteering in the community, and participating in theater are also included in Table 13.

\section{Discussion}

The purpose of this study was to identify the types of factors such as social anxiety and parenting style that are associated with adolescent use of social networking websites such as Facebook. Previous research has provided mixed conclusions as to how social anxiety impacts the use of social networking sites and most of these studies were conducted using young adult samples and not adolescents. Moreover, many of these studies did not examine specific parenting factors that may be influencing adolescent Facebook use. The current study addressed these limitations by administering online surveys to both adolescents and their parents so that comparisons could be made within the adolescent sample and between the adolescents and their

parents. The adolescent sample consisted of 102 males and 60 females between the ages of 16-18 and this vast difference in gender can be explained by the fact that the athletic events that were used primarily for recruitment were male sports. It should be noted that these events also 
included cheerleaders and band members which allowed for many female adolescent participants to be recruited.

\section{Social Anxiety and Facebook Use}

One aim of this study was to examine the association between Facebook use and social anxiety. Results revealed that level of social anxiety did not predict whether or not adolescents were likely to have a Facebook account. Specifically, adolescents who reported high levels of social anxiety were just as likely to have a Facebook account as those who report little to no social anxiety. Thus, these findings do not support the hypothesis that less socially anxious adolescents are more likely to use Facebook and suggests that Facebook bridges a social gap for some individuals who are not as comfortable interacting interpersonally. A small percentage of adolescents in this sample (less than 9\%) reported that they did not have an active Facebook account. This finding is similar to Stutzman (2006) in which only about $10 \%$ of college students had not created a Facebook profile page and suggests that Facebook use does not decline as one transitions from adolescence into adulthood.

The reason that adolescents use Facebook across level of social anxiety was also examined. In the current sample, $95 \%$ of adolescents with an active Facebook account reported that they use Facebook primarily to maintain existing friendships and only $5 \%$ preferred to make new friends. This is consistent with Subrahmanyam and Greenfield (2008) who found that adolescents were much more likely to use online communication to maintain existing friendships as opposed to meeting new people. This is also similar to findings by Pepek, Yermolayeva, \& Calvert (2009) in which about $85 \%$ of undergraduate college students used Facebook to communicate with friends. Furthermore, results revealed that level of social anxiety did not predict how adolescents use Facebook. In other words, adolescents who experience high social 
anxiety appear to be using Facebook for the same reason (to maintain existing friendships) as those who experience little to no social anxiety.

Contrary to what was predicted, the amount of time spent on Facebook was not associated with social anxiety. Specifically, adolescents who reported high social anxiety used Facebook just as much as those who reported low social anxiety. However, social anxiety did appear to have some impact on the number of friends on an adolescent's profile as a significant inverse relationship was observed. When comparing across level of social anxiety, a higher proportion of individuals with little to no social anxiety had a large number of friends ( 200 or more) on their Facebook profile. This finding lends some support for the "rich get richer" hypothesis in which more extroverted individuals are using Facebook as a means to expand their social network.

\section{Social Anxiety and Parental Control}

Another aim of the study was to examine the association between parental control and social anxiety. Results revealed that adolescents who reported higher levels of social anxiety also reported having more controlling parents. These findings were consistent across mothers and fathers and confirmed previous research on the impact of parental control on childhood anxiety (Rork \& Morris, 2009).

\section{Parenting Factors}

There were no significant differences with respect to adolescent report of maternal and paternal control. However, when examined across adolescent gender, fathers were more controlling with respect to their daughters than their sons and mothers were equally as controlling across child gender. These results suggest that fathers may treat their daughters differently with respect to communicating on Facebook and this is consistent with the research 
literature on sex-typing. For instance, Siegal (1987) conducted a meta-analysis on differential socialization behavior for parents and found support for the existence of father specific behaviors in which fathers' treatment of boys and girls differed significantly. The effects were most salient with respect to discipline and physical involvement and were weakest in affection and everyday speech. In contrast, sex-typing by mothers was rare in any of the studies that were reviewed.

Mothers and fathers also differed in the limits that they place on their teenager's behavior with mothers implementing more limits than fathers. Moreover, mothers were more likely to engage in monitoring of their child's online behavior. These results suggest that mothers may be taking a more active role in regulating the online behavior of their adolescent. Sons reported that both mothers and fathers engaged in more limit setting of their behavior compared to daughters. This may seem to be contrary to the earlier findings in which fathers engaged in more parental control with daughters compared to sons; however, the two measures share a very low correlation $(r=.01)$ which suggests that they are not measuring similar constructs. Mothers and fathers may be more concerned about their sons with respect to engaging in risky behavior both online and offline. This is not surprising in light of previous research has shown that males are more likely to engage in risk taking behavior such as drinking, using drugs, reckless driving, and engaging in unprotected sex (Byrnes, Miller, \& Schafer, 1999).

\section{Parenting Variables and Adolescent Risky Online Behavior}

Adolescents were questioned about whether or not they engaged in risky online behavior on Facebook. This behavior included posting photos of alcohol or drug use, posting sexually suggestive photos, posting foul language, and adding strangers as friends whom they have never met in person. Parental control, monitoring, and limit setting for mothers and fathers did not predict risky online behavior. Moreover, sons were just as likely as daughters to engage in risky 
online behavior. No previous research is available for comparison as this is the first study to examine risky online behavior by adolescents on Facebook. The lack of significant findings may be attributed to several factors based on the sample used in this study. First, only a small percentage of adolescents engaged in three out of the four risky online behaviors that were studied. The only risky online behavior that a majority of adolescents engaged in was adding strangers whom they had never met in person. Second, this sample was composed mostly of student athletes and members of the band and this represents a sample of adolescents who are fully engaged in extracurricular school activities. Research has shown that adolescents who spend unsupervised time with peers after school have higher rates of substance use, delinquency, susceptibility to peer pressure, and aggression compared to those who were engaged in school activities or were at home with their parents (Flannery, Williams, \& Vazsonyi, 1999). Thus, it is possible that the adolescents who participated in this study were not engaging in certain risky online behaviors because they were too preoccupied with school-related activities. Forman et al. (1995) compared high-risk behaviors of a group of adolescent male athletes to nonathletes and results suggested that participation in sports may lead to a significant decrease in drug and alcohol use, but may increase early sexual contact. This is also consistent with Miller et al. (1998) who found that male athletes reported higher rates of sexual activity compared to nonathletes. Conversely, the authors reported that female athletes engaged in significantly lower rates of sexual activity than female nonathletes. It is difficult to compare the current sample of participants to previous research samples as reporting of risky online behaviors for this study was generally very low and questionnaire items did not address rates of risky offline behavior.

\section{Depression}


Results revealed that adolescents who reported depressive symptoms were just as likely to have an active Facebook account as those who demonstrated little to no symptoms. Moreover, depressed individuals did not differ significantly from non-depressed people in the number of friends that they had on their Facebook profile page. While depressed adolescents may be less likely to engage in many social activities, these findings suggest that they are still using Facebook regularly. Future therapeutic interventions that target depression and anxiety may benefit from using online mediums to encourage individuals to engage in specific activities and ultimately become more social. For example, Boniel-Nissim and Barak (2011) studied the therapeutic value of blogging for adolescents who reported social-emotional difficulty in offline relationships with their peers. Participants were instructed to post at least two anonymous messages a week over ten weeks. Results showed that adolescents improved on measures of social-emotional functioning and offline social activity and the greatest gains were found for those who wrote blogs that were open to receiving feedback. While blogging in the traditional sense seems to be in decline in the United States (Zickuhr, 2010), blogging activity through social networks such as Facebook and Twitter appears to be expanding rapidly (Boniel-Nissim and Barak, 2011).

\section{Facebook Trends}

The majority of adolescents in this sample reported that they use Facebook primarily to communicate with existing friends. Moreover, most of them are logging into their account at least once a day and tend to spend 30 minutes or less on Facebook each time they log in. In addition, an overwhelming majority of adolescents had over 200 friends on their profile page with nearly half the sample having over 400 friends. Having such an exorbitant number of friends in one's network while having little time to be able to contact all of them brings up and 
interesting dilemma with respect to how friendship is defined in an online environment. The label of "existing friends" used in this study may have been too general to adequately account for the size and scope of online friendships. For example, some categories that could fall under the "existing friendship" umbrella for a Facebook friend may include: long-distance friendships, friends in close proximity, best friends, acquaintances, work friends, school friends, family members, friends of the family, friends since childhood, newly met friends, strangers, celebrities, organizations, and even people who are not their friends. Clearly, the use of the word "friend" cannot be used interchangeably between online and offline environments and future studies could examine the types of friends that adolescents are communicating with most when using Facebook. Interestingly, a majority of the sample also indicated that they have added friends to their Facebook profile whom they have never met offline, and this may account for the large number of friends that many adolescents have added to their Facebook profile.

Nearly all of the adolescents in the sample disclosed their full name as well as the name of their high school, and nearly half shared their e-mail address. Only a small minority of participants revealed their telephone number and even less displayed their home address. These findings suggest that older adolescents are reluctant to reveal information that may increase the probability of in-person interaction. These findings are also consistent with the finding that over $83 \%$ of the sample indicated that it is "important" to "very important" to be aware of potential problems with online communication compared to just 3\% who felt that it was "not important at all". Moreover, only a small number of adolescents reported that they had posted sexually suggestive photos or pictures of drug and alcohol use. Assuming they are being truthful, these findings demonstrate that adolescents in this sample are generally cautious about their behavior online and are aware of the potential dangers that exist with respect to online communication. 
Parents appeared to be very concerned about the potential problems associated with online communication; however, a larger percentage of mothers compared to fathers were following up their child's behavior on Facebook. For example, a significantly larger percentage of mothers reported that they checked their child's Facebook page regularly, were Facebook friends with their child, and had access to their child's username and password, and this is consistent with the results mentioned earlier that showed that mothers engaged in more parental monitoring compared to fathers.

\section{Study Limitations}

Several limitations should be considered when interpreting the results of this study. First, as was mentioned earlier, this study assessed a specific group of adolescents who actively engaged in extracurricular school activities and does not accurately account for adolescents who do not engage in high school athletic events. Moreover, the majority of participants were Caucasian and all were recruited from a single region of the country. Thus, homogeneity of this sample limits the ability to make generalizations beyond the current group of participants. A more diverse sample of adolescents may be a more representative sample with respect to a number of factors such as ethnicity, social anxiety, and patterns of Facebook use. Second, this study was descriptive as opposed to experimental; however, it would have been difficult to conduct a controlled study given the widespread use of Facebook in our present society. Third, adolescents completed these surveys online, and while they were assured that their data would be de-identified, they may have been concerned that their parents would know what they were disclosing, thus influencing their answers to be more conservative. This may be particularly true for the Adolescent Facebook Questionnaire in which only a small amount of participants reported having engaged in any risky online behavior. Fourth, only one type of social networking 
site was assessed in this study. It is possible that social anxiety and parenting factors may play a greater role in other social networking sites such as Youtube, Twitter, or dating websites. These are websites in which users do not have as much flexibility with respect to privacy as most users post information that is accessible for the general public.

\section{Future Directions}

As was stated earlier, only a small number of participants in this sample reported that they did not have an active Facebook account. Future studies could examine the specific factors that contribute to why adolescents do not use social networking sites like Facebook. For example, Baker and White (2011) found that an Australian sample of adolescents ages 13-18 did not use social networking sites due to lack of motivation, poor use of time, preference for other forms of communication, cyber-safety concerns, and engaging in other activities. Some of these reasons may also be true of the current sample given that the majority of the participants are already devoting much of their spare time to extracurricular high school activities (e.g. football, cheerleading, and band).

This study examined several reasons as to why adolescents use Facebook. A majority of participants reported that they created a Facebook page in order to maintain existing friendships and to a lesser account, to avoid boredom. A smaller percentage of adolescents reported that they joined Facebook to meet new people, express their opinion on certain issues, and find a romantic relationship. Future research could explore other reasons why adolescents use Facebook. For example, one issue that the Adolescent Facebook Questionnaire did not specifically address was finding out information about people whom they had just met offline. Subrahmanyam and Greenfield (2008) suggested that Facebook may be used as a screening tool in which additional information can be obtained about new entrants into one's offline world. The use of Facebook as 
a screener may also apply to the development of new romantic interests that have been initiated offline. Similar to adolescents, Sheldon (2008) concluded that young adults typically use Facebook to maintain existing friendships, to pass time, for entertainment, to avoid loneliness, and to find out information about other people. This last category represents an emerging pattern of behavior commonly known as lurking or stalking in which people spend exorbitant amounts of time looking at others people's personal information on Facebook. Pempek, Yermolayeva, and Calvert (2009) found that lurking behavior such as reading news feeds about what other friends are doing or observing other people's Facebook profile pages was occurring much more frequently than posting information on one's own page or updating one's own profile. The authors described one student from the study who admitted the experience was "creepy" if she had not seen or talked to a friend in years but was accessing personal information about that friend on her Facebook page. The tendency for people to prefer to observe others on Facebook for excessive amounts of time is intriguing and may warrant future research. Specifically, while socially anxiety may be not be associated with the rate in which adolescents use Facebook, there may be a difference in the nature in which they use Facebook. For example, socially anxious individuals may be engaging in less communication and greater "lurking" behavior than less socially anxious people.

This study did not take into account the means in which adolescents were accessing Facebook. For instance, accessing Facebook through smart phones and computer tablets (e.g. iPad) represents a rapidly growing trend in which people can be online anywhere as long as they have a cell phone or wireless Internet signal. Future research could address the impact that greater access to the Internet through technology has on the way in which teenagers use Facebook as well as a parent's ability to monitor and control its use. 
Finally, this study assessed the use of Facebook within an adolescent sample; however, since its inception, the use of Facebook has extended down to pre-adolescence and up to older adulthood. Future studies could explore the relevant characteristics of social networking sites that transcend the life-span and attract people to sign up and keep using them.

\section{Conclusion}

The present study examined social anxiety and Facebook use in an older adolescent sample. Level of social anxiety was not associated with having a Facebook account. Moreover, socially anxious adolescents are using Facebook at similar rates as their non-socially anxious peers and for similar reasons. Thus, contrary to what was predicted, these results provide some support for both the Social Compensation Hypothesis and the Social Enhancement Hypothesis, and this shows that these hypotheses do not necessarily have to be mutually exclusive (Peter et al., 2005; Kraut et al., 2002; Walther, 1996). Similar to young adults, adolescents are currently using Facebook primarily to maintain existing relationships although it is unclear as to the types of friends that adolescents are communicating with the most. This study also provided some insight into the role that parents play with respect monitoring their child's behavior. It would appear that mothers are taking a more active role in monitoring and regulating their children's behavior on Facebook compared to fathers.

The findings from this study show that Facebook is a very popular medium that a majority of high school-age adolescents are using to communicate with existing friends. Moreover, this is one of only a few studies to examine specific factors associated with Facebook use in an adolescent sample. Future studies should examine how the use of Facebook changes between adolescence and young adulthood as this is a period where social networks are greatly expanding (e.g college, work) while parental influences are diminishing. 


\section{References}

Acar, A. (2008). Antecedents and Consequences of Online Social Networking Behavior: The Case of Facebook, Journal of Website Promotion, 3, 62-83.

Ainsworth, M. D. S., Blehar, M. C., Waters, E., \& Wall, S. (1978). Patterns of attachment: A psychological study of the strange situation. Hillsdale, NJ: Erlbaum.

American Psychiatric Association. (2000). Diagnostic and statistical manual of mental disorders (4th ed. Text Revision). Washington, DC: Author.

Baker, R. K., \& White, K. M. (2011). In Their Own Word: Why Teenagers Don't Use Social Networking Sites. Cyberpsychology, Behavior, and Social Networking, 14, 395-398.

Baumrind, D. (1967). Child care practices anteceding three patterns of preschool behavior. Genetic Psychology Monographs, 75(1), 43-88.

Beidel, D. C., Borden, J. W., Turner, S. M., \& Jacob, R. G. (1989). The Social Phobia and Anxiety Inventory: Concurrent validity with a clinic sample. Behaviour Research and Therapy, 27, 573-576

Beidel, D. C., Christ, M. A., \& Long, P. J. (1991). Somatic Complaints in Anxious Children. Journal of Abnormal Child Psychology, 19, 659-670.

Beidel, D.C., Turner, S. M., \& Cooley, M. R. (1993). Assessing reliable and clinically significant change in social phobia: Validity of the Social Phobia and Anxiety Inventory. Behaviour, Research, and Therapy, 31, 331-337.

Beidel, D. C., Turner, S. M., \& Dancu, C V. (1985). Physiological, cognitive and behavioral aspects of social anxiety. Behaviour Research and Therapy, 23, 109-117.

Beidel, D. C., Turner, S. M., Stanley, M. A., \& Dancu, C. V. (1989). The social phobia and anxiety inventory: Concurrent and external validity. Behavior Therapy, 20, 417-427. 
Boniel-Nissim, M., \& Barak, A. (2011). The Therapeutic Value of Adolescents' Blogging About Social-Emotional Difficulties. Psychological Services. Advance online publication. doi: $10.1037 / \mathrm{a} 0026664$.

Boyd, D. M., \& Ellison, N. B. (2008). Social Network Sites: Definition, History, and Scholarship. Journal of Computer-Mediated Communication, 13, 210-230.

Byrnes, J. P., Miller, D. C., \& Schafer, W. D. (1999). Gender Differences in Risk Taking: A Meta-Analysis. Psychological Bulletin, 3, 367-383.

Chilcoat, H. D., \& Anthony, J. C. (1996). Impact of parent monitoring on initiation of drug use through late childhood. Journal of the American Academy of Child \& Adolescent Psychiatry, 35, 91-100.

Clark, D. B., Turner, S. M., Beidel, D. C., Donovan, J. E. Kirisci, L., \& Jacob, R. G. (1994). Reliability and Validity of the Social Phobia and Anxiety Inventory for Adolescents. Psychological Assessment, 6, 135-140.

Cohen, J. W. (1988). Statistical power analysis for the behavioral sciences $\left(2^{\text {nd }}\right.$ ed.). Hillsdale, NJ: Lawrence Erlbaum Associates.

Curtis, P. (1997). Mudding: Social phenomena in text-based virtual realities. In S. Kiesler (Ed.), Culture of the internet (pp.121-142). Mahwah, NJ: Erbaum.

DiClemente, R. J., Wingood, G. M., Crosby, R., Sionean, C., Cobb, B. K., Harrington, K., ... Oh, M. K. (2001). Parental monitoring: Association with adolescents' risk behaviors. Pediatrics, 107, 1363-1368.

Duggan, C., Sham, P., Minne, C., Lee, A., \& Murry, R. (1998). Quality of parenting and vulnerability to depression: Results from a family study. Psychological Medicine, 28, $185-191$. 
Eastin, M. S., Greenberg, B. S., \& Hofschire, L. (2006). Parenting the Internet. Journal of Communication, 56, 486-504.

Ellison, N. B., Steinfield, C., \& Lampe, C. (2007). The benefits of Facebook "friends": Social capital and college students' use of online social network sites. Journal of ComputerMediated Communication, 12, 1143-1168.

Flannery, D. J., Williams, L. L., \& Vazsonyi, A. T. (1999). WHO ARE THEY WITH AND WHAT ARE THEY DOING? Delinquent Behavior, Substance Use, and Early Adolescents' After-School Time. American Journal of Orthopsychiatry, 69, 247-253.

Fletcher, A. C., Steinberg, L., \& Williams-Wheeler, M. (2004). Parental influences on adolescent problem behavior. Revisiting Stattin and Kerr. Child Development, 75, 781-796.

Fogel, J., \& Nhemad, E. (2009). Internet social network communities: Risk taking, trust, and privacy concerns. Computers in Human Behavior, 25, 153-160.

Forman, E. S., Dekker, A. H., Javors, J. R., \& Davison, D. T. (1995). High-risk behaviors in teenage male athletes. Clinical Journal of Sports Medicine, 5, 36-42.

Frey, D., \& Carlock, C. (1989). Enhancing self-esteem. Muncie, IN: Accelerated Development, Inc.

Frojd, S., Kaltiala-Neino, R., \& Rimpela, M. (2007). The association of parental monitoring and family structure with diverse maladjustment outcomes in middle adolescent boys and girls. Nordic Journal of Psychiatry, 62, 296-303.

Greco, L. A. \& Morris, T. L. (2002). Paternal child-rearing style and child social anxiety: Investigation of child perceptions and actual father behavior. Journal of Psychopathology and Behavioral Assessment, 24, 259-267. 
Greco, L. A., \& Morris, T. L. (2005). Factors Influencing the Link Between Social Anxiety and Peer Acceptance: Contributions of Social Skills and Close Friendships During Middle Childhood. Behavior Therapy, 36, 197-205.

Gross, E. F., Juyonen, J., \& Gable, S. (2002). Internet Use and Well-being in Adolescence. Journal of Social Issues, 58, 75-90.

Hadley, W., Hunter, H. L., Tolou-Shams, M., Lescano, C., Thompson, A., Dononberg, G. ...Brown, L. K. (2011). Monitoring Challenges: A Closer Look at Parental Monitoring, Maternal Psychopathology, and Adolescent Sexual Risk. Journal of Family Psychology, 25, 319-323.

Healy, J. R., (2004). Initial development of an instrument measuring limit setting and monitoring in parents of adolescents. Unpublished doctoral dissertation. Alliant International University, Los Angeles, CA.

Herbert, J. D., Bellack, A. S., \& Hope, D. A. (1991). Concurrent validity of the Social Phobia and Anxiety Inventory. Journal of Psychopathology and Behavioral Assessment, 13, 357368.

Hinduja, S., \& Patchin, J. W. (2008). Personal information of adolescents on the Internet: A quantitative content analysis of MySpace. Journal of Adolescence, 31, 125-146.

Jacobson, K. C., \& Crockett, L. J. (2000). Parental monitoring and adolescent adjustment: An ecological perspective. Journal of Research on Adolescence, 10, 65-97.

Joinson, A. N. (2003). Understanding the psychology of Internet behavior: Virtual worlds, real lives. Basingstoke: Palgrave Macmillan.

Kaplan, L. S. (1995). Self-esteem is not our national wonder drug. School Counselor, 42, 341345. 
Kay, R. (2007, October). QuickStudy: Online social networks. These sites can facilitate connections in your industry or around the world. Computerworld. Retrieved August 15, 2009, from: http://www.computerworld.com/s/article/302652/Online_Social_Networks

Kazeniac, A. (2009, February). Social Networks: Facebook Takes Over Top Spot, Twitter Climbs. Retrieved September 26, 2011 from: http://blog.compete.com/2009/02/09/facebook-myspace-twitter-social-network/

Keijsers, L., Branje, S. J. T., VanderValk, I. E., \& Meeus, W. (2009). Reciprocal effects between parental solicitation, parental control, adolescent disclosure, and adolescent delinquency. Journal of Research on Adolescence, 20, 88-113.

Kerr, M., \& Stattin, H. (2000). What parents know, how they know it, and several forms of adolescent adjustment: Further support for a reinterpretation of monitoring. Developmental Psychology, 36, 366-388.

Kerr, M., Stattin, H., \& Burk, W. J. (2010). A reinterpretation of parental monitoring in longitudinal perspective. Journal of Research on Adolescence, 20, 39-64.

Kim, S. Y., \& Ge, X. (2000). Parenting and adolescent depressive symptoms in Chinese American Families. Journal of Family Psychology, 14, 420-435.

Knox, D., Daniels, V., Sturdivant, L., \& Zusman, M. E. (2001). College student use of the Internet for mate selection. College Student Journal, 35, 158-160.

Kohn, A. (1994). The truth about self-esteem. Phi Delta Kappan, 76, 272-283.

Kraut, R., Kiesler, S., Boneva, B., Cummings, J., Helgeson, V., \& Crawford, A. (2002). Internet paradox revisited. Journal of Social Issues, 58, 49-74.

Krohne, H. W., \& Hock, M. (1991). Relationships between restrictive mother-child interactions and anxiety of the child. Anxiety Research, 4, 109-124. 
Kujath, C. L. (2011). Facebook and MySpace: Complement or Substitute for Face-to-Face Interaction? Cyberpsychology, Behavior, and Social Networking, 14, 75-78.

Lenhart, A., \& Madden, M. (2007). Teens, Social Networks \& Safety An Overview. Pew Internet \& American Life Project. Retrieved August 15, 2009 from: http://www.pewinternet.org/Presentations/2007/Teens-Social-Networks-and-SafetyOnline.aspx

Livingstone, S., \& Helsper, E. (2008). Parental mediation and children's Internet use. Journal of broadcasting \& electronic media, 52, 581-599.

London, T. (1997). The case against self-esteem: Alternate philosophies toward self that would raise the probability of pleasurable and productive living. Journal of Rational-Emotive \& Cognitive Behavior Therapy, 15, 19-29.

Ma, M. L., \& Leung, L. (2005). Unwillingness-to-communicate, perceptions of the internet and self-disclosure in ICQ. Telematics and Informatics, 23, 22-37.

MacGill, A. R., (2007). Parent and teenager Internet use. Pew Internet \& American Life Project. Retrieved August 14, 2009 from http://www.pewinternet.org/pdfs/PIP_Teen_Parents_data_memo_Oct2007.pdf

Mackinnon, A. J., Henderson, A. S., \& Andrews, G. (1991). The Parental Bonding Instrument: a measure of perceived or actual parental behavior? Acta Psychiatrica Scandinavica, 83, 153-159.

Marsh, H., \& Holmes, I. (1990). Multidimensional self-concepts: Construct validation of responses by children. American Educational Research Journal, 27, 89-117. 
Mattick, R. P., \& Clarke, J. C. (1998). Development and validation of measures of social phobia scrutiny fear and social interaction anxiety. Behaviour Research and Therapy, 36, 455470.

McCown, J.A., Fischer, D., Page, R., \& Homant, M. (2001). Internet relationships: People who meet people. CyberPsychology and Behavior, 4, 593-596.

McKenna, K. Y., \& Bargh, J. A. (2000). Plan 9 from cyberspace: The implications of the internet for personality and social psychology. Personality and Social Psychology Review, 4, 5775.

McTeague, L. M., Lang, P. J., Laplante, M., Cuthbert, B. N., Strauss, C. C. \& Bradley, M. M. (2009). Fearful imagery in social phobia: Generalization, comorbidity, and physiological reactivity. Biological Psychiatry, 65, 374-382.

Miller, K. E., Sabo, D. F., Farrell, M. P., Barnes, G. M., \& Melnick, M. J. (1998). The Different Worlds of Boys and Girls. Journal of Health and Social Behavior, 39, 108-123.

Mruk, C. (1995). Self-esteem: Research, theory, and practice. New York: Springer.

National Institute on Drug Abuse (February, 2002). Risk and protective factors in drug abuse prevention. NIDA Notes: Drug Abuse Prevention Research Update, 16(6). Retrieved March 27, 2012 from: www.nida.nih.gov/NIDA_Notes/NNVol16N6/Risk.html.

Olivares, J., Garcia-Lopez, L. G., Hidalgo, M. D., \& Caballo, V. (2004). Relationships Among Social Anxiety Measures and Their Invariance. European Journal of Psychological Assessment, 20, 172-179.

Pallant, J. (2007). SPSS Survival Manual. A Step by Step Guide to Data Analysis using SPSS for Windows third edition. New York: Open University Press. 
Papacharissi, A., \& Rubin, A. (2000). Predictors of internet use. Journal of Broadcasting and Electronic Media, 44, 75-196.

Parker G. (1983). Parental Overprotection: A Risk Factor in Psychosocial Development. New York: Grune \& Stratton.

Parker, G. (1986). Validating an experiential measure of parental style: the use of a twin sample. Acta Psychiatrica Scandinavica, 73, 22-27.

Parker, G., Tupling, H., \& Brown, L.B. (1979) A Parental Bonding Instrument. British Journal of Medical Psychology, 52, 1-10.

Pempek, T. A., Yermolayeva, Y. A., \& Calvert, S. L. (2009). College students's social networking experiences on Facebook. Journal of Applied Developmental Psychology, 30, $227-238$.

Peter, J., Valkenburg, P. M., \& Schouten, A.P. (2005). Developing a model of adolescent friendship formation on the internet. CyberPsychology \& Behavior, 8, 423-430.

Peters, L. (2000). Discriminant validity of the Social Phobia and Anxiety Inventory (SPAI), the Social Phobia Scale (SPS), and the Social Interaction Anxiety Scale (SIAS). Behaviour Research \& Therapy, 38, 943-950.

Pope, A., McHale, S., \& Craighead, E. (1988). Self-esteem enhancement with children and adolescents. New York: Pergamon Press.

Powell, L., Richmond, V. P., \& Williams, G. C. (2011). Social Networking and Political Campaigns: Perceptions of Candidates as Interpersonal Constructs. North American Journal of Psychology, 13, 331-342. 
Racz, S. J., \& McMahon, R. J. (2011). The Relationship Between Parental Knowledge and Monitoring and Child and Adolescent Conduct Problems: A 10-Year Update. Clinical Child Family Psychology Review, 14, 377-398.

Rork, K. E., \& Morris, T. L. (2009). Influence of Parenting Factors on Childhood Social Anxiety: Direct Observation of Parental Warmth and Control. Child and Family Behavior Therapy, 31, 220-235.

Rose, A., Koo, H. P., Bhaskar, M., Anderson, K., White, G., \& Jenkins, R. (2005). The influence of primary caregivers on the sexual behavior or early adolescents. Journal of Adolescent Health, 37, 135-144.

Rosen, L. D., Cheever, N. A., Carrier, \& L. M. (2008). The association of parenting style and child age with parental limit setting and adolescent MySpace behavior. Journal of Applied Developmental Psychology, 29, 459-471.

Sagrestano, L. M., Holmbeck, G. N., Paikoff, R. L., \& Fendrich, M. (2003). A longitudinal examination of familial risk factors for depression among inner-city African American adolescents. Journal of Family Psychology, 17, 108-120.

Sheldon, P. (2008). The Relationship Between Unwillingness-to-Communicate Students' Facebook Use. Journal of Media Psychology, 20, 67-75.

Siegal, M. (1987). Are Sons and Daughters Treated More Differently by Fathers than by Mothers? Developmental Review, 7, 183-209.

Stattin, H., \& Kerr, M. (2000). Parental monitoring: A reinterpretation. Child Development, 71, 1072-1085.

Stevens, S. B., \& Morris, T. L. (2007). College Dating and Social Anxiety: Using the Internet as a Means of Connecting to Others. CyberPsychology \& Behavior, 5, 680-688. 
Stutzman, F. (2006). An evaluation of identity-sharing behavior in social network communities. iDMAa Journal, 3, 1-7. Retrieved on August 9, 2009 from: http://www.units.muohio.edu/codeconference/papers/papers/stutzman_track5.pdf

Subrahmanyam, K., \& Greenfield, P. (2008). Online Communication and Adolescent Relationships. The Future of Children, 18, 119-146.

Subrahmanyam, K., Reich, S. M., Waechter, N., \& Guadalupe, E. (2008). Online and offline social networks: Use of social networking sites by emerging adults. Journal of Applied Developmental Psychology, 29, 420-433.

Tabachnick, B. G., \& Fidell, L. S. (2007). Using multivariate statistics ( $^{\text {th }}$ ed.). Boston: Person Education.

Tafarodi, R. W., \& Ho, C. (2006). Implicit and Explicit Self-Esteem: What Are We Measuring? Canadian Psychology, 47, 195-202.

Turner, S. M., Beidel, D. C., \& Dancu, C. V. (1996). SPAI-Social Phobia and Anxiety Inventory: Manual. Toronto: Multi-Health Systems.

Turner, S. M., Beidel, D. C., Dancu, C. V., \& Stanley, M. A. (1989). An empirically derived inventory to measure social fears and anxiety: The Social Phobia and Anxiety Inventory. Psychological Assessment, 1, 35-40.

Turner, S. M., Stanley, M. A., Beidel, D. C., \& Bond, L. (1989). The Social Phobia and Anxiety Inventory: Construct Validity. Journal of Psychopathology and Behavioral Assessment, $11,221-234$.

Valcke, M., Bonte, S., De Wever, B., \& Rots, I. (2010). Internet Parenting Styles and the Impact on Internet Use of Primary School Children. Computers and Education, 55, 454-464. 
Valkenburg, P. M., Peter, J., \& Schouten, A. P. (2006). Friend Networking Sites and Their Relationship to Adolescents' Well-Being and Social Self-Esteem, CyberPsychology \& Behavior, 9, 584-590.

Valkenburg, P. M., Schouten, A.P., \& Peter, J. (2005). Adolescents' identity experiments on the Internet. New Media \& Society, 7, 383-402.

Walther, J. B. (1996). Computer-mediated communication: Impersonal, interpersonal, and hyperpersonal interaction. Communication Research, 23, 3-43.

Wang, R., Bianchi, S. M., \& Raley, S. B. (2005) Teenager's Internet use and family rules: a research note. Journal of Marriage and Family, 67, 1249-1258.

Ward, C. C., \& Tracey, T. J. G. (2004). Relation of shyness with aspects of online relationship involvement. Journal of Social and Personal Relationships, 21, 611-623.

Wilborg, I. M., \& Dahl, A. A. (1997). The recollection of parental rearing styles in patients with panic disorder. Acta Psychiatrica Scandinavica, 96, 58-63.

Williams, A. L., \& Merten, M. (2008). A Review of Online Social Networking Profiles by Adolescents: Implications for Future Research and Intervention. Adolescence, 43, 253 274.

Wylie, R. (1989). Measures of self-concept. Lincoln: University of Nebraska Press.

Zickuhr, K. (2010). Generations online in 2010. PEW Internet \& American Life Project. Retrieved January 22, 2011 from: http://pewresearch.org/pubs/1831/generations-online2010

Zuckerberg, M., Hughs, C., Moskovitz, \& D., Saverin, E. (2011). Statistics: People on Facebook. Retrieved November 2, 2011 from: http://www.facebook.com/press/info.php?statistics 
Adolescent Facebook Use 53

Zywica, J., \& Danowski, J. (2008). The Faces of Facebookers: Investigating Social Enhancement and Social Compensation Hypotheses; Predicting Facebook and Offline Popularity from Sociability and Self-Esteem, and Mapping the Meanings of Popularity with Semantic Networks. Journal of Computer-Mediated Communication, 14, 1-14. 
Table 1

Descriptive statistics and gender comparisons for adolescent-report measures

\begin{tabular}{|c|c|c|c|c|c|c|c|}
\hline \multirow[b]{2}{*}{ Measure } & \multicolumn{2}{|c|}{ Males } & \multicolumn{2}{|c|}{ Females } & \multirow[b]{2}{*}{$t$} & \multirow[b]{2}{*}{$(d f)$} & \multirow[b]{2}{*}{$p$} \\
\hline & $M$ & $S D$ & $M$ & $S D$ & & & \\
\hline SPAI & 38.37 & 25.87 & 38.70 & 28.99 & .08 & 160 & .94 \\
\hline \multicolumn{8}{|l|}{ PBI } \\
\hline Control (mothers) & 12.12 & 6.19 & 12.30 & 5.12 & .21 & 160 & .84 \\
\hline Control (fathers) & 10.05 & 5.30 & 12.80 & 7.31 & 2.54 & 96 & .01 \\
\hline Care (mothers) & 30.47 & 4.35 & 28.97 & 5.42 & 1.94 & 160 & .05 \\
\hline Care (fathers) & 26.98 & 6.32 & 24.43 & 9.10 & 1.91 & 93 & .06 \\
\hline \multicolumn{8}{|l|}{ PLMS-A } \\
\hline Total (mothers) & 3.38 & .67 & 3.36 & .75 & .16 & 145 & .87 \\
\hline Total (fathers) & 2.98 & .73 & 2.83 & .93 & 1.09 & 141 & .28 \\
\hline Monitoring (mothers) & 3.72 & .67 & 3.87 & .84 & 1.17 & 145 & .24 \\
\hline Monitoring (fathers) & 3.25 & .77 & 3.15 & 1.13 & .67 & 141 & .50 \\
\hline Limit setting (mothers) & 2.90 & .84 & 2.64 & .81 & 1.80 & 145 & .07 \\
\hline Limit setting (fathers) & 2.60 & .82 & 2.39 & .81 & 1.46 & 141 & .15 \\
\hline
\end{tabular}

Note. $N=162$ for the SPAI and PBI measures. Also, $N=145$ for the PLMS-A report of mothers and 143 for the PLMS-A report of fathers. 
Adolescent Facebook Use 55

Table 2

Mean PLMS-P scores for fathers and mothers

\begin{tabular}{|c|c|c|c|c|c|c|c|}
\hline \multirow[b]{2}{*}{ PLMS-P } & \multicolumn{2}{|c|}{ Fathers } & \multicolumn{2}{|c|}{ Mothers } & \multirow[b]{2}{*}{$t$} & \multirow[b]{2}{*}{$(d f)$} & \multirow[b]{2}{*}{$p$} \\
\hline & $M$ & $S D$ & $M$ & $S D$ & & & \\
\hline Total PLMS-P Score & 3.47 & .68 & 3.73 & .54 & 2.62 & 173 & .01 \\
\hline Limit setting & 3.20 & .87 & 3.32 & .73 & .92 & 173 & .92 \\
\hline Monitoring & 3.67 & .68 & 4.03 & .52 & 3.67 & 173 & $<.01$ \\
\hline
\end{tabular}

Note. $N=44$ for fathers and 131 for mothers. 
Adolescent Facebook Use 56

Table 3

Correlations Among PLMS-A and PLMS-P items for adolescents and mothers and fathers

PLMS-P Mothers PLMS-P Fathers

PLMS-A Items

$\overline{r p} r \frac{p}{r}$

1. My parent regularly communicates with the

$\begin{array}{llll}.50 & <.01 \quad .39 & <.01\end{array}$
parents of my friends.

2. My parent knows who I am communicating $.30<.01$ with online.

3. Negative or alarming events in my community .12 .16 change what my parent allows me to do.

4. My parent makes sure I understand his/her $.23<.01$ .06 .70 concerns and goals when he/she makes rules that I may not like.

5. My parent knows what I am doing at all times. .28 $<.01$

6. My parent knows how I spend my money.

$.32<.01$

$.56<.01$

7. I contact my parent if my plans change.

8. My parent is aware of how much time I spend on Facebook.

9. My parent sets limits on the amount of time I spend on Facebook.

10. My parent is aware of the activities I engage in .37 on Facebook.

11. My parent sets limits on the activities I engage .3 in on Facebook.

12. My parent always enforces the limits that he/she sets for me concerning Facebook use. 
Adolescent Facebook Use 57

Table 4

Active Facebook accounts for adolescents and parent knowledge of a Facebook account

\begin{tabular}{|c|c|c|c|c|c|}
\hline & \multicolumn{2}{|c|}{ Adolescents on Facebook } & \multicolumn{3}{|c|}{ Parent Knowledge of Facebook Account } \\
\hline & Yes & No & Yes & No & Don't know \\
\hline Total & $91 \%$ & $9 \%$ & $91 \%$ & $8 \%$ & $1 \%$ \\
\hline Males & $95 \%$ & $5 \%$ & $88 \%$ & $11 \%$ & $1 \%$ \\
\hline Females & $97 \%$ & $3 \%$ & $97 \%$ & $3 \%$ & $0 \%$ \\
\hline
\end{tabular}

Note. $N=89$ for adolescent males and 58 for adolescent females. Also, $N=43$ for fathers and 131 for mothers. 
Table 5

Comparisons of adolescent ratings of mothers and fathers on parental control, parental monitoring, and parental limit setting

\begin{tabular}{|c|c|c|c|c|c|c|c|}
\hline \multirow[b]{2}{*}{ Measure } & \multicolumn{2}{|c|}{ Mothers } & \multicolumn{2}{|c|}{ Fathers } & \multirow[b]{2}{*}{$t$} & \multirow[b]{2}{*}{$p$} & \multirow[b]{2}{*}{$\eta$} \\
\hline & $M$ & $S D$ & $M$ & $S D$ & & & \\
\hline Control (PBI) & 12.23 & 5.52 & 11.80 & 6.25 & 1.75 & .08 & .01 \\
\hline \multicolumn{8}{|l|}{ PLMS-A } \\
\hline Monitoring & 3.76 & .74 & 3.21 & .93 & 5.56 & $<.01$ & .10 \\
\hline Limit setting & 2.78 & .82 & 2.52 & .82 & 2.65 & $<.01$ & .02 \\
\hline
\end{tabular}

Note. $N=322$ for the adolescent report of parental control. Also, $N=294$ for the PLMS-A report of parental monitoring and limit setting. 
Adolescent Facebook Use 59

Table 6

Adolescent number of logins to a Facebook account

\begin{tabular}{|c|c|c|c|c|c|}
\hline & $\begin{array}{c}\text { Once a week } \\
\text { or less }\end{array}$ & $\begin{array}{l}\text { 2-3 times } \\
\text { a week }\end{array}$ & $\begin{array}{l}\text { 4-6 times } \\
\text { a week }\end{array}$ & Once a day & $\begin{array}{l}\text { More than } \\
\text { once a day }\end{array}$ \\
\hline Total & $6.1 \%$ & $17.7 \%$ & $21.8 \%$ & $26.5 \%$ & $27.9 \%$ \\
\hline Males & $5.6 \%$ & $22.5 \%$ & $20.2 \%$ & $28.1 \%$ & $23.6 \%$ \\
\hline Females & $6.9 \%$ & $10.3 \%$ & $24.1 \%$ & $24.1 \%$ & $34.5 \%$ \\
\hline
\end{tabular}


Table 7

Amount of time spent using Facebook each time the adolescent logs in

\begin{tabular}{lcccccc}
\hline & $<15$ min & $15-30 \mathrm{~min}$ & $31-60 \mathrm{~min}$ & $1-2$ hours & $2-3$ hours & $>3$ hours \\
\hline Total & $32.7 \%$ & $33.3 \%$ & $21.8 \%$ & $7.5 \%$ & $2.0 \%$ & $2.7 \%$ \\
Males & $33.7 \%$ & $36.0 \%$ & $19.1 \%$ & $7.9 \%$ & $2.2 \%$ & $1.1 \%$ \\
Females & $31.0 \%$ & $29.3 \%$ & $25.9 \%$ & $6.9 \%$ & $1.7 \%$ & $5.2 \%$ \\
\hline
\end{tabular}

$N=89$ for adolescent males and 58 for adolescent females. 
Adolescent Facebook Use 61

Table 8

Number of friends on the

\begin{tabular}{|c|c|c|c|c|c|c|c|}
\hline & \multicolumn{7}{|c|}{ Number of friends on the adolescent's Facebook profile } \\
\hline & $<10$ & $10-20$ & $21-50$ & $51-100$ & $101-200$ & $201-400$ & $>400$ \\
\hline Total & $1.4 \%$ & $2.7 \%$ & $.7 \%$ & $7.5 \%$ & $8.2 \%$ & $35.4 \%$ & $44.2 \%$ \\
\hline Males & ------ & $3.4 \%$ & $1.1 \%$ & $11.3 \%$ & $6.7 \%$ & $36.0 \%$ & $41.6 \%$ \\
\hline Females & $3.4 \%$ & $1.7 \%$ & ------ & $1.7 \%$ & $10.3 \%$ & $34.5 \%$ & $48.3 \%$ \\
\hline
\end{tabular}

$N=89$ for adolescent males and 58 for adolescent females. 
Adolescent Facebook Use 62

Table 9

Adolescent report of type of information disclosed and parent knowledge of the disclosure

\begin{tabular}{|c|c|c|c|c|c|c|}
\hline & \multicolumn{2}{|c|}{ Adolescent Report } & \multicolumn{4}{|c|}{ Parents Knowledge of Facebook Use } \\
\hline & \multirow{2}{*}{$\begin{array}{c}\text { Males } \\
\text { Yes }\end{array}$} & \multirow{2}{*}{$\begin{array}{c}\text { Females } \\
\text { Yes }\end{array}$} & \multicolumn{2}{|c|}{ Mothers } & \multicolumn{2}{|c|}{ Fathers } \\
\hline & & & Yes & Don't Know & Yes & Don't Know \\
\hline Full Name & $74 \%$ & $60 \%$ & $58 \%$ & $8 \%$ & $54 \%$ & $26 \%$ \\
\hline E-mail Address & $45 \%$ & $47 \%$ & $44 \%$ & $15 \%$ & $33 \%$ & $33 \%$ \\
\hline School Name & $75 \%$ & $74 \%$ & $73 \%$ & $12 \%$ & $58 \%$ & $33 \%$ \\
\hline Phone Number & $33 \%$ & $28 \%$ & $11 \%$ & $12 \%$ & $7 \%$ & $33 \%$ \\
\hline Home Address & $16 \%$ & $22 \%$ & $2 \%$ & $12 \%$ & $0 \%$ & $33 \%$ \\
\hline
\end{tabular}

Note. $N=89$ for adolescent males and 58 for adolescent females. Also, $N=43$ for fathers and 131 for mothers. 
Table 10

Adolescent report of risky online behavior and parent knowledge of adolescent behavior

\begin{tabular}{|c|c|c|c|c|c|c|c|}
\hline \multirow[t]{2}{*}{ Item \# } & \multicolumn{2}{|c|}{$\begin{array}{l}\text { Adolescent } \\
\text { Report }\end{array}$} & \multicolumn{3}{|c|}{$\begin{array}{l}\text { Parent Knowledge of } \\
\text { Adolescent Behavior }\end{array}$} & \multicolumn{2}{|c|}{$\begin{array}{c}\text { Kappa Correlation } \\
\text { Coefficient }\end{array}$} \\
\hline & Yes & No & Yes & No & Don't know & $r$ & $p$ \\
\hline $\begin{array}{l}\text { Posted photos of } \\
\text { drug/alcohol use }\end{array}$ & $5 \%$ & $95 \%$ & $5 \%$ & $89 \%$ & $6 \%$ & .23 & $<.01$ \\
\hline $\begin{array}{l}\text { Posted sexually } \\
\text { suggestive photos }\end{array}$ & $3 \%$ & $97 \%$ & $<1 \%$ & $94 \%$ & $5 \%$ & .33 & $<.01$ \\
\hline $\begin{array}{l}\text { Posted foul or } \\
\text { suggestive photos }\end{array}$ & $15 \%$ & $85 \%$ & $12 \%$ & $75 \%$ & $13 \%$ & .43 & $<.01$ \\
\hline $\begin{array}{l}\text { Added strangers to } \\
\text { Facebook page }\end{array}$ & $61 \%$ & $39 \%$ & $25 \%$ & $49 \%$ & $26 \%$ & .08 & .17 \\
\hline
\end{tabular}

Note. $N=89$ for adolescent males and 58 for adolescent females. Also, $N=43$ for fathers and 131 for mothers. 
Adolescent Facebook Use 64

Table 11

Adolescent report of privacy settings on their Facebook profile

\begin{tabular}{lccccc}
\hline & $\begin{array}{c}\text { Most stringent } \\
\text { settings }\end{array}$ & $\begin{array}{c}\text { Friends } \\
\text { only }\end{array}$ & $\begin{array}{c}\text { Friends of } \\
\text { friends }\end{array}$ & $\begin{array}{c}\text { People in } \\
\text { their network }\end{array}$ & $\begin{array}{c}\text { Everyone has } \\
\text { access }\end{array}$ \\
\hline Total & $4 \%$ & $70 \%$ & $11 \%$ & $5 \%$ & $9 \%$ \\
Males & $3 \%$ & $61 \%$ & $16 \%$ & $7 \%$ & $14 \%$ \\
Females & $7 \%$ & $86 \%$ & $3 \%$ & $2 \%$ & $2 \%$ \\
\hline
\end{tabular}

Note. $N=89$ for adolescent males and 58 for adolescent females. 
Table 12

Adolescent and parent report of parental monitoring of adolescent Facebook account

\begin{tabular}{|c|c|c|c|c|c|c|c|}
\hline & \multicolumn{5}{|c|}{ Monitoring of Facebook use by the parent } & \multicolumn{2}{|c|}{$\begin{array}{l}\text { Computer allowed in } \\
\text { child's bedroom? }\end{array}$} \\
\hline & Daily & Weekly & Monthly & $\begin{array}{c}<\text { Once a } \\
\text { month }\end{array}$ & Never & Yes & No \\
\hline \multicolumn{8}{|c|}{$\begin{array}{l}\text { Adolescent report } \\
\text { of mothers }\end{array}$} \\
\hline Total & $17 \%$ & $35 \%$ & $12 \%$ & $16 \%$ & $20 \%$ & $72 \%$ & $28 \%$ \\
\hline Males & $12 \%$ & $34 \%$ & $14 \%$ & $18 \%$ & $23 \%$ & $66 \%$ & $34 \%$ \\
\hline Females & $24 \%$ & $36 \%$ & $10 \%$ & $14 \%$ & $16 \%$ & $81 \%$ & $19 \%$ \\
\hline \multicolumn{8}{|c|}{$\begin{array}{c}\text { Adolescent report } \\
\text { of fathers }\end{array}$} \\
\hline Total & $5 \%$ & $18 \%$ & $6 \%$ & $10 \%$ & $60 \%$ & $68 \%$ & $32 \%$ \\
\hline Males & $2 \%$ & $17 \%$ & $7 \%$ & $11 \%$ & $63 \%$ & $64 \%$ & $36 \%$ \\
\hline Females & $9 \%$ & $21 \%$ & $5 \%$ & $9 \%$ & $56 \%$ & $74 \%$ & $26 \%$ \\
\hline \multicolumn{8}{|c|}{ Parent Report } \\
\hline Total & $25 \%$ & $31 \%$ & $16 \%$ & $15 \%$ & $12 \%$ & $51 \%$ & $49 \%$ \\
\hline Mothers & $30 \%$ & $35 \%$ & $12 \%$ & $15 \%$ & $8 \%$ & $52 \%$ & $48 \%$ \\
\hline Fathers & $11 \%$ & $19 \%$ & $28 \%$ & $16 \%$ & $26 \%$ & $53 \%$ & $47 \%$ \\
\hline
\end{tabular}

Note. $N=89$ for adolescent males and 58 for adolescent females. Also, $N=43$ for fathers and 131 for mothers. 
Table 13

Adolescent report of activities engaged in outside of Facebook

\begin{tabular}{lcccc}
\hline Activity & Every day & $\begin{array}{c}\text { Several times } \\
\text { a week }\end{array}$ & Once a week & Never \\
\hline Play sports & $67 \%$ & $22 \%$ & $2 \%$ & $9 \%$ \\
Play a musical instrument & $13 \%$ & $7 \%$ & $9 \%$ & $71 \%$ \\
Outdoor activities & $28 \%$ & $28 \%$ & $29 \%$ & $15 \%$ \\
Working in the church & $1 \%$ & $10 \%$ & $40 \%$ & $49 \%$ \\
Spending time in academic clubs & $5 \%$ & $14 \%$ & $29 \%$ & $52 \%$ \\
Spending time in school organizations & $8 \%$ & $22 \%$ & $45 \%$ & $25 \%$ \\
Volunteering in the community & $6 \%$ & $10 \%$ & $45 \%$ & $39 \%$ \\
Acting/Theater & $3 \%$ & $5 \%$ & $6 \%$ & $86 \%$
\end{tabular}

Note. $N=162$ 
Appendix A

\section{Information About You and Your Family}

Your Name:

Your Age:

Your relationship to the child:

Your Race:

American Indian or Alaskan Native

Asian or Pacific Islander

Black

White

Your Ethnicity:

Hispanic Origin

Not of Hispanic Origin
Your Child's Name:

Child's Date of Birth:

Child's Sex: ___ Boy _ Girl
Your child's Race:

American Indian or Alaskan Native

Asian or Pacific Islander

Black

White

\section{Your child's Ethnicity:}

Hispanic Origin

Not of Hispanic Origin

Occupation: Please provide your job position or title, NOT the name of your employer. For example, if you are a teacher at the local high school, please state "high school teacher". If you are retired, please state "retired" as well as your prior occupation. If you do not work outside the home, please state "stay at home parent" or "unemployed".

What is your occupation? (please be specific)

\section{Highest Level of Education Completed:}

Did not complete high school

High School

Some College

College Degree

Graduate Degree

Please complete the following information about your spouse (if applicable):

Your spouse's age:

Your spouse's occupation:

Your spouse's highest level of education completed:

Did not complete high school

High School

Some College

College Degree

Graduate Degree 
Your spouse's Race:

American Indian or Alaskan Native

Asian or Pacific Islander

Black

White

Your spouse's Ethnicity:

Hispanic Origin

Not of Hispanic Origin 
Appendix B

\section{Parental Knowledge of Adolescent Facebook Use Questionnaire}

1. I generally use the Internet to: (Please check only $\underline{\boldsymbol{O N E}}$ box)

$\square$ Browse websites $\quad \square \quad \square \quad$ Communicate with people

2. When I use the Internet to communicate, I do so in order to: (Please check only $\underline{\boldsymbol{O N E}}$ box)
Meet new people
Communicate with existing friends

3. I have an active Facebook account. (Please check only $\underline{\boldsymbol{O N E}}$ box)

$$
\square \text { Yes } \square \text { No }
$$

If you answered $\underline{\mathbf{Y e s}}$, please continue with item \#4.

If $\underline{\mathbf{N o}}$, then proceed to item \#5

4. I generally use Facebook to: (Please check only $\underline{\boldsymbol{O N E}}$ box).

$$
\text { Meet new people } \quad \square \text { Communicate with existing friends }
$$

5. My child generally uses the Internet to: (Please check only $\underline{\boldsymbol{O N E}}$ box)

$$
\text { Browse websites } \square \text { Communicate with people }
$$

6. When my child uses the Internet to communicate, he/she does so in order to:

(Please check only $\underline{\mathrm{ONE}}$ box)

$\square$ Meet new people $\quad \square$ Communicate with existing friends

7. My child has an active Facebook account. (Please check only $\underline{\boldsymbol{O N E}}$ box)

$$
\square \text { Yes } \square \text { No }
$$

If you answered $\underline{\text { Yes, }}$ please continue with item \#8.

If $\underline{\text { No, }}$, then proceed to item \#21

8. My child generally uses Facebook to: (Please check only $\underline{\boldsymbol{O N E}}$ box).
Meet new people
Communicate with existing friends

9. On average, my child spends

(Check only one box) on Facebook each time he or she logs in.

I do not know less than 15 minutes 15-30 minutes 31 minutes to 1 hour between 1-2 hours between 2-3 hours greater than 3 hours 
10. The number of times my child logs onto Facebook each week is: (Check only one box)
I do not know
1 time or less
2-3 times
4-6 times
once a day
more than once a day

11. The total number of friends on my child's Facebook profile is
$\square$ I do not know
less than 10
$10-20$
$21-50$
$51-100$
$101-200$
201-400
$\square$ More than 400

12. My child is a member of the following social networking websites: (Check all that apply).

I do not know if my child is a member of these sites

$\square$ My child is not a member of any other sites

\section{MySpace}

$\square$ Twitter

$\square$ Other: (Flixter, Linkedin, etc.)

13. My child has disclosed the following information on his/her Facebook page:

$\begin{array}{llll}\text { Full name } & \square \text { Yes } & \square \text { No } & \square \text { I do not know } \\ \text { School name } & \square \text { Yes } & \square \text { No } & \square \text { I do not know } \\ \text { E-mail address } & \square \text { Yes } & \square \text { No } & \square \text { I do not know } \\ \text { Phone number } & \square \text { Yes } & \square \text { No } & \square \text { I do not know } \\ \text { Home address } & \square \text { Yes } & \square \text { No } & \square \text { I do not know }\end{array}$

For the following items, please check the answer choice that applies to your child.

14. My child has posted photos on his/her Facebook account involving alcohol or drug use.
$\square$ Yes $\quad \square$ No $\quad \square$ I don't know

15. My child has posted sexually suggestive photos of himself/herself or of his/her friends on his/her Facebook account.
Yes
No
I don't know

16. My child has posted foul or sexually suggestive language on his/her Facebook account.
$\square$ Yes
No
I don't know 
17. My child has added friends to his/her Facebook profile whom he/she has never met offline.

$$
\square \text { Yes } \quad \square \text { No } \quad \square \text { I don't know }
$$

18. I look at my child's Facebook page.
Daily
Weekly
Monthly
Less than once a month
Never

19. I view photographs on my child's Facebook page.

$\square$ Daily $\square$ Weekly $\square$ Monthly $\square$ Less than once a month $\square$ Never

20. I read the material posted on my child's Facebook page.

$\square$ Daily $\square$ Weekly $\square$ Monthly $\square$ Less than once a month $\square$ Never

21. I allow my child to have a computer with Internet access in his/her bedroom.

$\square$ Yes $\quad \square$ No

22. I have talked to my child about any potential problems related to online communication.

$\square$ Yes $\quad \square$ No

23. It is important to be aware of the potential problems associated with online communication.

$\square$ Yes $\square$ No 


\section{Appendix C}

\section{Parent Limit Setting and Monitoring Scale-Parental Report}

For the following, please indicate the answer that best describes your relationship with your teenager.

1. I regularly communicate with the parents of my teenager's friends.

$$
\text { 0-Never 2-Rarely 2-Sometimes 3-Often 4-Always }
$$

2. I know who my teen is communicating with online.

$$
\text { 0-Never 2-Rarely 2-Sometimes } \quad \text { 4-Always }
$$

3. Negative or alarming events in my community change what I allow my teenager to do.

$$
\text { 0-Never 1-Rarely 2-Sometimes 3-Often 4-Always }
$$

4. I make sure my teenager understands my concerns and goals when I make rules that he/she may not like.
0 -Never
1- Rarely
2-Sometimes
3- Often
4-Always

5. I know what my teen is doing at all times.
0 -Never
1- Rarely
2-Sometimes
3- Often
4-Always

6. I know how my teenager spends his/her money.
0 -Never
1- Rarely
2-Sometimes
3- Often
4-Always

7. My teenager contacts me if his/her plans change.
0 -Never
1- Rarely
2-Sometimes
3- Often
4-Always

8. I am aware of how much time my teen spends on Facebook.
0 -Never
1- Rarely
2-Sometimes
3- Often
4-Always

9. I set limits on the amount of time my teen spends on Facebook.
0 -Never
1- Rarely
2-Sometimes
3- Often
4-Always

10. I am aware of the activities my teen is engaged in on Facebook.
0 -Never
1- Rarely
2-Sometimes
3- Often
4-Always

11. I set limits on the activities my teen engages in on Facebook.
0 -Never
1- Rarely
2-Sometimes
3- Often
4-Always

12. I always enforce the limits I set for my teen concerning Facebook use.
0 -Never
1- Rarely
2-Sometimes
3- Often
4-Always 


\section{Appendix D}

\section{Adolescent Facebook Use Questionnaire}

1. I generally use the Internet to: (Please check only $\underline{\boldsymbol{O N E}}$ box)

$\square$ Browse websites $\square$ Communicate with people

2. When I use the Internet to communicate, I do so in order to: (Please check only $\underline{\boldsymbol{O N E}}$ box)

$\square$ Meet new people $\quad \square$ Communicate with existing friends

3. I have an active Facebook account. (Please check only $\underline{\text { ONE }}$ box)

$\square$ Yes $\quad \square$ No

If you answered $\underline{\mathbf{Y e s}}$, please continue with item \#4.

If $\underline{\text { No, }}$, then proceed to item \#22

4. I generally use Facebook to: (Please check only $\underline{\boldsymbol{O N E}}$ box).

Meet new people $\quad \square$ Communicate with existing friends

5. On average, I spend on Facebook each time I log in. (Check only one box)

$\square$ less than 15 minutes

15-30 minutes

31 minutes to 1 hour

between 1-2 hours

between 2-3 hours

more than 3 hours

6. The number of times I log onto Facebook each week is: (Check only one box)

1 or less

2-3 times

4-6 times

once a day

more than once a day

7. The total number of friends on my Facebook profile is:

less than 10

10-20

21-50

51-100

101-200

201-400

More than 400 
8. I am currently a member of the following social networking websites: (Check all that apply).

I am not a member of any other sites

\section{MySpace}

Twitter

Other: (Flixter, Linkedin, etc.)

9. I have disclosed the following information on my Facebook page: (Check all that apply).

$\square$ full name

$\square$ e-mail address

school name

$\square$ phone number

home address

10. I created a Facebook account in order to be able to: (Check all that apply).

Maintain existing friendships

$\square$ Make new friends

$\square$ Keep in touch with friends that I rarely ever see

Find a romantic relationship

Avoid boredom

Express my opinion on various issues

11. I engage in the following activities when I'm on Facebook: (Check one box for each activity)

Editing my profile

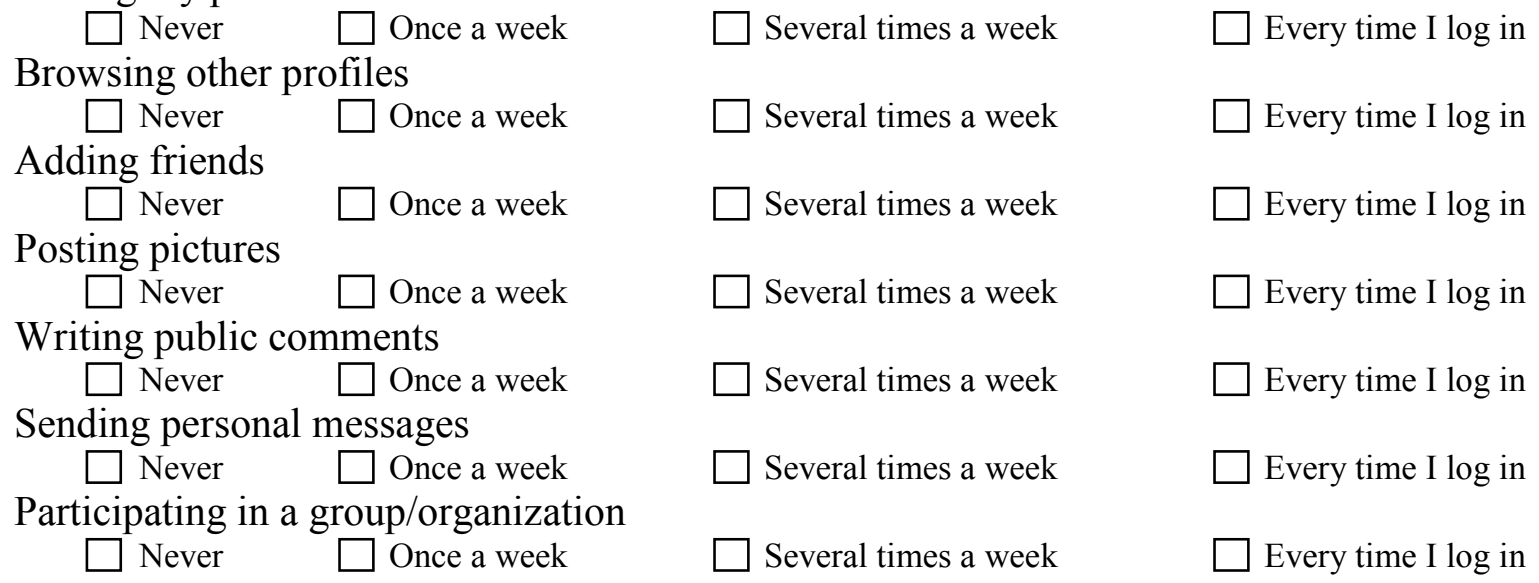

For the following items, please check the answer choice that applies to you. 
12. I have posted photos on my Facebook account involving alcohol or drug use.

$\square$ Yes $\square$ No

13. I have posted sexually suggestive photos of myself or of my friends on my Facebook account.<smiles>[AlH2]O[AlH2]</smiles>

14. I have posted foul or sexually suggestive language on my Facebook account.

$\square$ Yes $\quad \square$ No

15. I have added friends to my Facebook profile whom I have never met offline.

$\square$ Yes $\quad \square$ No

16. My mother looks at my Facebook page.

$\square$ Daily $\square$ Weekly $\square$ Monthly $\square$ Less than once a month $\square$ Never

17. My father looks at my Facebook page.

$\square$ Daily $\square$ Weekly $\square$ Monthly $\square$ Less than once a month $\square$ Never

18. My mother views photographs on my Facebook page.

$\square$ Daily $\square$ Weekly $\square$ Monthly $\square$ Less than once a month $\square$ Never

19. My father views photographs on my Facebook page.

$\square$ Daily $\square$ Weekly $\square$ Monthly $\square$ Less than once a month $\square$ Never

20. My mother reads the material posted on my Facebook page.

$\square$ Daily $\square$ Weekly $\square$ Monthly $\square$ Less than once a month $\square$ Never

21. My father reads the material posted on my Facebook page.

$\square$ Daily $\square$ Weekly $\square$ Monthly $\square$ Less than once a month $\square$ Never

22. My mother allows me to have a computer with Internet access in my bedroom.

$\square$ Yes $\quad \square$ No

23. My father allows me to have a computer with Internet access in my bedroom.

$\square$ Yes $\quad \square$ No

24. My mother has talked to me about any potential problems related to online communication.

$\square$ Yes $\quad \square$ No

25. My father has talked to me about any potential problems related to online communication.

$\square$ Yes $\square$ No

26. It is important to be aware of the potential problems associated with online communication.

$\square$ Yes $\square$ No 


\section{Appendix E}

\section{Parental Bonding Instrument - Mother}

This questionnaire lists various attitudes and behaviors of your mother.

Please place a check mark in the most appropriate box next to each item.

\begin{tabular}{|c|c|c|c|c|}
\hline & All the time & Some of the time & Not very often & Never \\
\hline 1. My mother speaks to me in a warm and friendly voice. & $\square$ & $\square$ & $\square$ & $\square$ \\
\hline 2. My mother helps me as much as I need. & $\square$ & $\square$ & $\square$ & $\square$ \\
\hline 3. My mother lets me do those things I like doing. & $\square$ & $\square$ & $\square$ & $\square$ \\
\hline 4. My mother seems emotionally cold to me. & $\square$ & $\square$ & $\square$ & $\square$ \\
\hline 5. My mother understands my problems and worries & $\square$ & $\square$ & $\square$ & $\square$ \\
\hline 6. My mother is affectionate to me. & $\square$ & $\square$ & $\square$ & $\square$ \\
\hline 7. My mother likes me to make my own decisions. & $\square$ & $\square$ & $\square$ & $\square$ \\
\hline 8. My mother wants me to grow up. & $\square$ & $\square$ & $\square$ & $\square$ \\
\hline 9. My mother tries to control everything I do. & $\square$ & $\square$ & $\square$ & $\square$ \\
\hline 10. My mother invades my privacy. & $\square$ & $\square$ & $\square$ & $\square$ \\
\hline 11. My mother enjoys talking things over with me. & $\square$ & $\square$ & $\square$ & $\square$ \\
\hline 12. My mother smiles at me. & $\square$ & $\square$ & $\square$ & $\square$ \\
\hline 13. My mother treats me like a baby. & $\square$ & $\square$ & $\square$ & $\square$ \\
\hline 14. My mother understands what I need or want. & $\square$ & $\square$ & $\square$ & $\square$ \\
\hline 15. My mother lets me decide things for myself. & $\square$ & $\square$ & $\square$ & $\square$ \\
\hline 16. My mother makes me feel I wasn’t wanted. & $\square$ & $\square$ & $\square$ & $\square$ \\
\hline 17. My mother can make me feel better when I am upset. & $\square$ & $\square$ & $\square$ & $\square$ \\
\hline 18. My mother talks with me a lot. & $\square$ & $\square$ & $\square$ & $\square$ \\
\hline 19. My mother tries to make me feel dependent on her. & $\square$ & $\square$ & $\square$ & $\square$ \\
\hline 20. My mother feels I can't look after myself unless she's around. & $\square$ & $\square$ & $\square$ & $\square$ \\
\hline 21. My mother gives me as much freedom as I want. & $\square$ & $\square$ & $\square$ & $\square$ \\
\hline 22. My mother lets me go out as often as I want. & $\square$ & $\square$ & $\square$ & $\square$ \\
\hline 23. My mother is overprotective of me. & $\square$ & $\square$ & $\square$ & $\square$ \\
\hline 24. My mother praises me. & $\square$ & $\square$ & $\square$ & $\square$ \\
\hline 25. My mother lets me dress any way I please. & $\square$ & $\square$ & $\square$ & $\square$ \\
\hline
\end{tabular}




\section{Appendix E}

\section{Parental Bonding Instrument - Father}

This questionnaire lists various attitudes and behaviors of your father.

Please place a check mark in the most appropriate box next to each item.

\begin{tabular}{|c|c|c|c|c|}
\hline & All the time & Some of the time & Not very often & Never \\
\hline 1. My father speaks to me in a warm and friendly voice. & $\square$ & $\square$ & $\square$ & $\square$ \\
\hline 2. My father helps me as much as I need. & $\square$ & $\square$ & $\square$ & $\square$ \\
\hline 3. My father lets me do those things I like doing. & $\square$ & $\square$ & $\square$ & $\square$ \\
\hline 4. My father seems emotionally cold to me. & $\square$ & $\square$ & $\square$ & $\square$ \\
\hline 5. My father understands my problems and worries & $\square$ & $\square$ & $\square$ & $\square$ \\
\hline 6. My father is affectionate to me. & $\square$ & $\square$ & $\square$ & $\square$ \\
\hline 7. My father likes me to make my own decisions. & $\square$ & $\square$ & $\square$ & $\square$ \\
\hline 8. My father wants me to grow up. & $\square$ & $\square$ & $\square$ & $\square$ \\
\hline 9. My father tries to control everything I do. & $\square$ & $\square$ & $\square$ & $\square$ \\
\hline 10. My father invades my privacy. & $\square$ & $\square$ & $\square$ & $\square$ \\
\hline 11. My father enjoys talking things over with me. & $\square$ & $\square$ & $\square$ & $\square$ \\
\hline 12. My father smiles at me. & $\square$ & $\square$ & $\square$ & $\square$ \\
\hline 13. My father treats me like a baby. & $\square$ & $\square$ & $\square$ & $\square$ \\
\hline 14. My father understands what I need or want. & $\square$ & $\square$ & $\square$ & $\square$ \\
\hline 15. My father lets me decide things for myself. & $\square$ & $\square$ & $\square$ & $\square$ \\
\hline 16. My father makes me feel I wasn't wanted. & $\square$ & $\square$ & $\square$ & $\square$ \\
\hline 17. My father can make me feel better when I am upset. & $\square$ & $\square$ & $\square$ & $\square$ \\
\hline 18. My father talks with me a lot. & $\square$ & $\square$ & $\square$ & $\square$ \\
\hline 19. My father tries to make me feel dependent on him. & $\square$ & $\square$ & $\square$ & $\square$ \\
\hline 20. My father feels I can't look after myself unless he's around. & $\square$ & $\square$ & $\square$ & $\square$ \\
\hline 21. My father gives me as much freedom as I want. & $\square$ & $\square$ & $\square$ & $\square$ \\
\hline 22. My father lets me go out as often as I want. & $\square$ & $\square$ & $\square$ & $\square$ \\
\hline 23. My father is overprotective of me. & $\square$ & $\square$ & $\square$ & $\square$ \\
\hline 24. My father praises me. & $\square$ & $\square$ & $\square$ & $\square$ \\
\hline 25. My father lets me dress any way I please. & $\square$ & $\square$ & $\square$ & $\square$ \\
\hline
\end{tabular}




\section{Appendix F}

\section{Parent Limit Setting and Monitoring Scale-Adolescent Report}

For the following, please indicate the answer that best describes your relationship with your teenager.

1. My parent regularly communicates with the parents of my friends.

$$
\text { 0-Never 2-Rarely 2-Sometimes } \quad \text { 3-Often } \quad \text {-Always }
$$

2. My parent knows who I am communicating with online.

$$
\text { 0-Never 2-Rarely 2-Sometimes } \quad \text { 4-Always }
$$

3. Negative or alarming events in my community change what my parent allows me to do.

$$
\text { 0-Never 1-Rarely 2-Sometimes 3-Often 4-Always }
$$

4. My parent makes sure I understand his/her concerns and goals when he/she makes rules that I may not like.
0 -Never
1- Rarely
2-Sometimes
3- Often
4-Always

5. My parent knows what I am doing at all times.
0 -Never
1- Rarely
2-Sometimes
3- Often
4-Always

6. My parent knows how I spend my money.
0 -Never
1- Rarely
2-Sometimes
3- Often
4-Always

7. I contact my parent if my plans change.
0 -Never
1- Rarely
2-Sometimes
3- Often
4-Always

8. My parent is aware of how much time I spend on Facebook.
0 -Never
1- Rarely
2-Sometimes
3- Often
4-Always

9. My parent sets limits on the amount of time I spend on Facebook.
0 -Never
1- Rarely
2-Sometimes
3- Often
4-Always

10. My parent is aware of the activities I engage in on Facebook.
0 -Never
1- Rarely
2-Sometimes
3- Often
4-Always

11. My parent sets limits on the activities I engage in on Facebook.
0 -Never
1- Rarely
2-Sometimes
3- Often
4-Always

12. My parent always enforces the limits that he/she sets for me concerning Facebook use.
0 -Never
1- Rarely
2-Sometimes
3- Often
4-Always 